\title{
A NOVEL TIME DOMAIN PROTECTION TECHNIQUE FOR MULTI-TERMINAL HVDC NETWORKS UTILISING TRAVELLING WAVE ENERGY.
}

\section{BY}

\section{(1) Monday Ikhide (Corresponding Author)}

Department of Electrical Engineering, Staffordshire University, College Road, Stoke-on-

$$
\text { Trent, ST4 2ED, UK }
$$

**Present Address: Faculty of Engineering, Environment and Computing, Coventry University, Priority Street,

CVI 5FB, UK; email: monday.ikhide@coventry.ac.uk

\section{(2) Sarath. B. Tennakoon}

Department of Electrical Engineering, Staffordshire University, College Road, Stoke-on-

Trent, ST4 2ED, UK; email: s.b.tennakoon@staffs.ac.uk

\section{(3) Alison. L. Griffiths}

Department of Electrical Engineering, Staffordshire University, College Road, Stoke-on-

Trent, ST4 2ED, UK; Email: a.I.Griffiths@staffs.ac.uk

\section{(4) Hengxu Ha}

G.E Grid Solutions, Redhill Business Park, Stafford, ST16 1WT, UK

Email: hengxu.ha@ge.com

(5) Sankara Subramanian

G.E Grid Solutions, Redhill Business Park, Stafford, ST16 1WT, UK

Present address: Grid Engineering and innovation consultants, Stafford. STI7 4 TR. UK

email: support@geaiconsultants.co.uk

(6) Andrzej J. Adamczyk,

G.E Grid Solutions, Redhill Business Park, Stafford, ST16 1WT, UK

Email: andrzej.adamczyk@ge.com 


\section{Abstract}

Fault vulnerability and protection issues are major challenge in realising multi-terminal HVDC transmission system, also termed HVDC grids. This paper presents a novel time domain and transient based protection technique for application to HVDC grids. The technique utilises the energy of the forward and backward travelling waves produced by a fault to distinguish between internal and external faults. For an internal fault, the calculated forward or backward travelling wave energy for a pre-set time duration following the occurrence of a fault must exceed a predetermined setting otherwise the fault is external. This characteristic is largely due to the DC inductor located at the cable ends, as per HVDC breakers or fault current limiters, which provides attenuation for the high frequency transients resulting from an external fault. The ratio between the forward travelling wave energy and the backward travelling wave energy provides directional comparison. For a forward directional fault with respect to a local relay, this ratio must be less than unity whereas the ratio is greater than unity for a reverse directional fault. The simulation results presented based on full scale Modular Multilevel Converter Based HVDC grid shows the suitability of the proposed technique. An advantage of this technique is that it is non-unit based and as such no communication delay is incurred. Furthermore, it is simple as it does not require complex mathematical/DSP technique; and as such can be easily implemented at each independent relay since it will require minimal hardware resources hence reduces cost.

Keywords: $H V D C$ grid protection, transient based protection, travelling wave energy, 


\section{Introduction}

The availability of fast fault detection algorithms is a prerequisite for the secure, safe and reliable operation of Multi-terminal HVDC systems (or DC grids) [1,2]. Although several attempts have been made in recent past to develop DC line protection algorithms for DC grids [3-16], however, trends and recent advances made in the development of DC grids still create opportunities for further research and studies in DC grid protection. Generally, DC fault current rises rapidly due to the low reactance in DC systems compared to AC systems, thus reaching damaging levels in a few milliseconds [2]. Therefore, fault detection, discrimination and clearance in DC grids must be completed before the fault current reaches a damaging level to ensure that the faulty section is isolated quickly while maintaining the continuity of service delivery in the healthy section of the grid. However, a major issue is selectivity; as only the faulty section should be isolated in the event of a fault. The challenge is to realise this using single-ended measurements only, without information from the remote end terminal via a communication link.

A possible arrangement of a four terminal HVDC grid consisting of four cable sections is shown in Figure 1.1. Key advantages of DC grids include optimal asset utilisation, increased efficiency and reliability as well as reduced costs; since existing onshore converter stations could be interconnected with future and proposed offshore converter stations to develop DC grids. The development of DC grids will also open new opportunities for energy trading among regional countries $[17,18]$. As shown in Figure 1.1 , in the event of a DC short circuit or fault along say cable section 1 , only cable section 1-2 of the grid should be isolated, while maintaining continuity of service in cable sections 2, 3 and 4 . In the light of these, and to guarantee the reliability and security of service delivery, transient based protection techniques are ideal candidates 
for DC grid protection if the protection scheme must be reliable, secure and dependable.

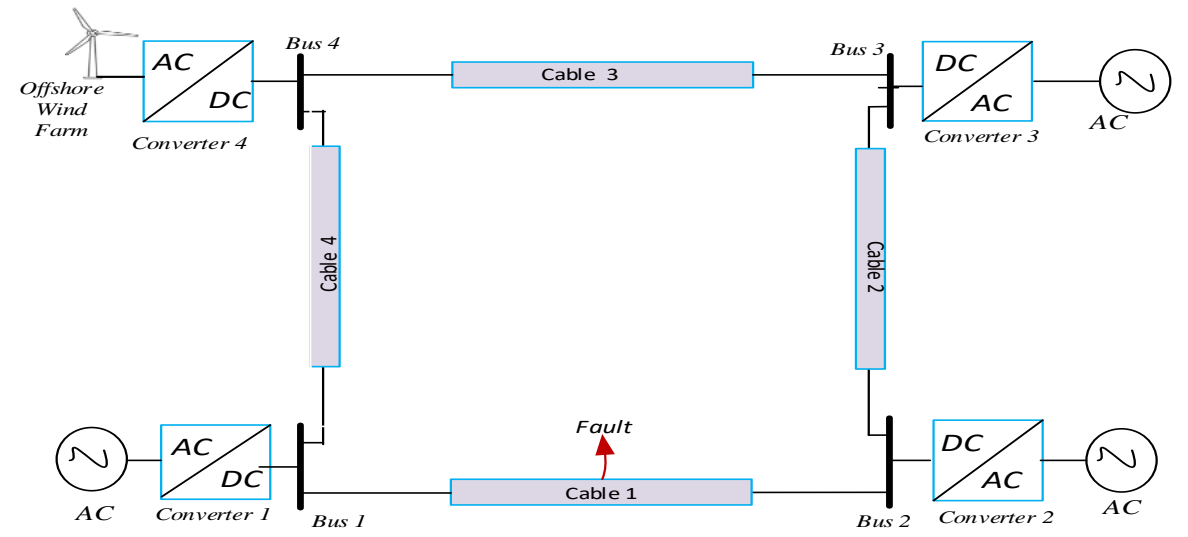

Fig. 1.1 Conceptual four terminal mesh HVDC Grid

Transient based protection techniques utilise the fault generated transient components to detect the occurrence of faults, thereby making it possible to detect the fault very quickly, and well before the steady state. The conventional current derivative (di/dt) principle, the under-voltage $(\Delta V)$ technique, voltage derivative protection technique $(d v / d t)$, the polarity identification technique and the travelling wave-based protection (TWBP) techniques all belong to the class of transient based protection technique. However, there are some limitations in adopting these principles for the primary protection of DC grids. For example, the $\Delta V$ protection technique [19] and $d v / d t$ protection principle [3] cannot provide directional discrimination when used in isolation and as such will require a separate element to discriminate against reverse faults occurring on an adjacent feeder on the grid. Furthermore, the $\Delta V$ protection principle will be too slow to act especially for long distance remote internal fault where the fault resistance may be significantly larger than that of an external fault close to the busbar terminal of an adjacent feeder in the forward direction. 
The di/dt technique developed for DC traction systems such as $d i / d t+\Delta T$ or $\Delta i+\Delta T$; [20], would require long time window if adopted for the protection of DC grids. Therefore, for DC grid protection, the initial di/dt must be accurately measured at fault inception to guarantee the reliability of the protection scheme. Generally, the effect of oscillations will also impact on the integrity and reliability of the measured di/dt since it is dependent on how far from $t=0$ (where $\mathrm{t}=0$ is the time of fault) the measurements are taken, noting that the $d i / d t$ keeps changing until the fault current profile attains its global maximum or minimum.

In the light of these, recent studies have proposed a hybrid protection scheme such as those utilising $\Delta V+d v / d t+d i / d t$, [7] and $d v / d t+d i / d t[10]$. Reference [6] also proposed the use of wavelet coefficients, utilising three variables, namely current, voltage, and $d v / d t$ for identification of the faulty branch in DC grid, however this will involve computational burden as well as consuming hardware resources. The polarity identification technique proposed in [23], including those comparing the polarity of $d i / d t$ at local and remote end relay terminals [9], those utilising the polarity of the sum or difference of the currents at local and remote end relay terminals $[4,5]$, would require communication between the local and remote end relays and as such their suitability is largely dependent on the integrity and reliability of the communication link. Reference [14] proposed a boundary protection scheme utilising additional shunt capacitors installed at the boundaries, however for a meshed DC grid, this method would require an additional element to discriminate against the high frequency transient resulting from a reverse fault occurring at an adjacent feeder.

Existing TWBP techniques developed or proposed for traditional HVAC systems such as in [21-24] as well as those developed for two terminal HVDC systems [25-29], could be deployed as a primary protection of DC grids, however the following concerns are worth nothing. 
i. The reliance on communication link between the local and remote end relay; which results in delays. Furthermore, the reliability of the protection scheme is largely dependent on the integrity of the communication link.

ii. The reliance on multiple and successive reflections between the fault and the relay terminals which also results in communication delay

iii. The challenge of distinguishing between the wave arriving at the relay terminal from the fault point and that due to reflection from the remote end terminals, which may involve some form of DSP techniques. Furthermore, it will also require more hardware resources from the implementation stand point.

iv. The successive reflections between the fault point and the local relay might not be captured due to attenuation in the cable. This is particularly the case for long distance remote internal fault.

v. The reliance on complex signal processing technique to study the frequency spectrum of the fault induced transient, which results in extra computational burden.

vi. The requirement of a separate element to discriminate against the high frequency transient resulting from a reverse fault occurring at an adjacent feeder, thus requiring further studies.

A recent study [16] proposed a TWBP principles for application to DC grids. The study compares the polarities of the transient energy of the travelling wave measured at the local and remote end relay to provide directional comparison; and hence discriminating between internal and external fault on the DC link. The simulation results presented including, sensitivity analysis shows the effectiveness of the proposed principle, however the technique relies on communication links which will results in communication delay. As the cable length increases, the propagation delay time of the travelling wave will imposed some limitations on the speed of operation of the 
protection scheme. Generally, for unit protection scheme, the integrity of the protection scheme is largely dependent on the reliability of the communication links.

The protection principle presented in this paper utilises the energy in the forward and backward travelling waves following the occurrence of a fault to determine whether a fault has occurred on a section or branch of the grid. For an internal fault, the calculated forward and backward travelling wave energy (TWE) for a pre-set time duration following the occurrence of a fault must exceed a predetermined setting otherwise the fault is external. This characteristic is largely due to the DC inductor located at the cable ends which provides attenuation for the high frequency transients resulting from an external fault. The ratio between the forward travelling wave energy (FTWE) and the backward travelling wave energy (BTWE) provides directional discrimination. For a forward fault this ratio must be less than unity whereas the ratio is greater than unity for a reverse fault. Compared to other TWBP in literature, key advantages of the proposed technique include the following

- It is fast in operation and able to react to fault within $0.5 \mathrm{~ms}$ following fault inception. It is non-unit based and as such does not require communication channel; hence no delays. Furthermore, it is not dependent on the integrity of the communication channel.

- It does not rely on multiple reflections between the fault and the relay terminals.

- It relies only on the first incident wave arriving at the relay terminal to provide discrimination.

- It does not require complex mathematical computation to distinguish between those waves travelling from the point of fault to the relay terminal and those reflected from remote end relay terminals. Therefore, it would require minimal hardware resources, such reduced memory space and processing resources in modern micro-processor relays, which ultimately will reduce cost. 
Furthermore, the use of the travelling wave energy, which is representative of the area under the travelling wave power curve ensures security of the protection algorithm.

The rest of the paper is organised as follows. Section 2 explains the basic philosophy of the protection principle. The protection principle is presented in section 3 ; this includes the conditions for directional discrimination and that distinguishing between internal and external faults. The flow chart, with a description of the various units is also explained in section 3 . In section 4, the proposed protection scheme is validated based on full scale HVDC grid made available in PSCAD. The sensitivity analysis of the protection scheme considering wider cases of fault scenarios as well as effect of noise are also presented in section 4 , whilst section 5 concludes the paper with some consideration for future studies.

\section{Basic Philosophy}

Figure 1 shows a two terminal transmission network with an arbitrary fault location and, hence resulting in a forward and backward travelling wave as shown. The relays, $R_{A}$ and $R_{B}$ have been located to measure the travelling wave components as they arrive at the busbars, $A$ and $B$ respectively.

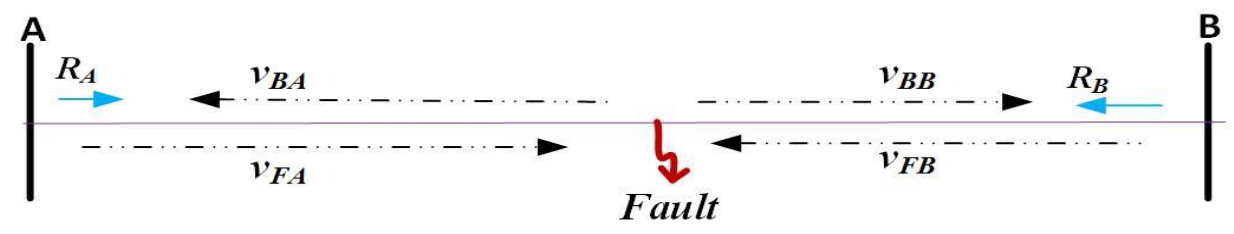

Fig. 1.1 Traveling waves on a transmission 


$$
\begin{aligned}
& V_{F A}=\text { Forward voltage travelling wave (FVTW) with respect to relay A } \\
& V_{F B}=\text { Forward voltage travelling wave (FVTW) with respect to relay } \mathrm{B} \\
& V_{B A}=\text { Backward voltage travelling wave (BVTW) with respect to relay A } \\
& V_{B B}=\text { Backward voltage travelling wave (BVTW) with respect to relay B }
\end{aligned}
$$

The term "forward" or "backward" are arbitrary, and it depends on the assumed reference direction of current flow in the relay. In this study, it has been assumed that the current flowing in the relay is from the busbar into the line as shown. Therefore, all waves in the same direction with that of the relay is regarded as forward travelling wave, whilst all waves travelling in opposite direction are regarded as backward travelling wave.

\subsection{Expressions for the travelling wave components}

Considering terminal A of Figure 2.1; and regardless of time and space variations, the voltages and currents along a line in the transient mode caused by a switching, fault or any other change of state processes are related by the expression given in Equations (2.1) and (2.2) [21,22].

$$
\begin{aligned}
& v_{F A}(x, t)=Z_{C} i_{F A}(x, t) \\
& v_{B A}(x, t)=-Z_{C} i_{B A}(x, t)
\end{aligned}
$$

$x$ represents the position of the wave at any instant in time. $Z_{C}(=\sqrt{ } L / C)$ is the lossless characteristic impedance of the line. The current associated with the FVTW is directly proportional to its voltage, with its constant of proportionality being $+1 / Z_{c}$; whilst the current associated with the BVTW is also directly proportional to its voltage, but with its constant of proportionality being $-1 / Z_{c}$. Therefore, the FVTW and the associated current waves are of the same sign whereas the BVTW and the associated current are 
of opposite sign. The general solution for the voltage and current along a line and as a function of time is the superposition of two waves, thus

$$
\begin{aligned}
& v_{T}(x, t)=v_{F A}(x, t)+v_{B A}(x, t) \\
& i_{T}(x, t)=\frac{1}{Z_{C}}\left(v_{F A}(x, t)-v_{B A}(x, t)\right)
\end{aligned}
$$

$v_{T},(x, t), i_{T}(x, t)$ are the total voltages and currents on the line at any instant and point on the transmission medium assuming that a step voltage is applied to a de-energised network. Generally, they represent the actual superimposed quantities ( $\Delta v_{D C}$ and $\left.\Delta i_{D C}\right)$ respectively) following the occurrence of faults on a transmission line. Thus

$$
\begin{aligned}
& \Delta v_{D C}=v_{D C(\text { inst })}-v_{D C(s s)} \\
& \Delta i_{D C}=i_{D C(\text { inst })}-i_{D C(s s)}
\end{aligned}
$$

Where the subscripts, "inst" and "ss" represents the instantaneous and steady state components respectively. From Equations (2.3) and (2.4) and noting that $x=0$ at the relaying point, the following expressions for $v_{F A}$ and $v_{B A}$ can therefore be written.

$$
\begin{aligned}
& v_{F A}(x, t)=\frac{\Delta v_{D C}(t)+Z_{c} \Delta i_{D C}(t)}{2} \\
& v_{B A}(x, t)=\frac{\Delta v_{D C}(t)-Z_{c} \Delta i_{D C}(t)}{2}
\end{aligned}
$$

\subsubsection{Power and energy of travelling waves}

Generally, as waves travel along a transmission line, power is developed by the forward and backward travelling wave. These large powers accompanying the travelling waves tend to produce strong effects in the high voltage networks. However, the duration of the effects at any given point and time on the network is limited by the high speed of propagation of the waves, hence their effects are minimal. Generally, for equal voltages, the power is thus higher in cables than in overhead lines. This is largely of different sign. Now, since the power is the product of current and voltage, the power 
developed by the superimposed components of voltage and current, $\Delta P_{D C}$ at the relay terminal following the occurrence of a fault is the product of the superimposed voltage and current ( $\Delta v_{D C}$ and $\Delta i_{D C}$ respectively). Therefore, from Equations (2.3) and (2.4) and also noting that $\mathrm{x}=0$ at the relay terminal, the following can be written.

$$
\Delta P_{D C}(t)=v_{F A}(t)+v_{B A}(t) \times \frac{1}{z_{C}} v_{F A}(t)-v_{B A}(t)
$$

Further simplification results in

$$
\Delta P_{D C}(t)=\frac{1}{Z_{C}} v_{F A}(t)^{2}-\frac{1}{Z_{C}} v_{F A}(t)^{2}
$$

The power contained in the forward and reverse travelling wave $P_{F W}$ and $P_{R W}$ can therefore be expressed as

$$
\begin{gathered}
P_{F W}(t)=\frac{1}{Z_{C}} v_{F A}(t)^{2} \\
P_{B W}(t)=-\frac{1}{Z_{C}} v_{B A}(t)^{2}
\end{gathered}
$$

Therefore the power contained in the forward travelling wave has positive polarity whereas that contained in the reverse travelling wave has negative polarity. From Equations (2.7) and (2.8), the following can be written

$$
\begin{gathered}
P_{F W}(t)=\frac{1}{4 Z_{C}}\left(\begin{array}{c}
\Delta v_{D C}{ }^{2}+2 \Delta v_{D C} \times \Delta i_{D C} \times Z_{C} \\
+\Delta i_{D C}{ }^{2} \times Z_{C}{ }^{2}
\end{array}\right) \\
P_{B W}(t)=-\frac{1}{4 Z_{C}}\left(\begin{array}{c}
\Delta v_{D C}{ }^{2}-2 \Delta v_{D C} \times \Delta i_{D C} \times Z_{C} \\
+\Delta i_{D C}{ }^{2} \times Z_{C}{ }^{2}
\end{array}\right)
\end{gathered}
$$

In the same way, the energy of the forward and backward travelling waves $E_{F W}$ and $E_{B W}$ respectively, can also be expressed. Thus 


$$
\begin{gathered}
E_{F W}=\int_{t_{d}}^{t_{m}} P_{F W}(t) d t \\
E_{B W}=\int_{t_{d}}^{t_{m}} P_{B W}(t) d t
\end{gathered}
$$

The quantity, $t_{m}-t_{d}$ is the time interval when measurements are taken; $t_{d}$ is the time of arrival of the travelling wave at the relay and $t_{m}$ is the time during when measurements are taken. In this paper, $E_{F W}$ and $E_{B W}$ were determined by Simpson's rule, thus

$E_{F W}=\frac{\Delta t}{3}\left(P_{F W_{0}}+4 P_{F W_{1}}+2 P_{F W_{2}}+4 P_{F W_{3}}+2 P_{F W_{4}}+\cdots+2 P_{F W_{N-1}}+4 P_{F W_{N-1}}+\right.$ $\left.P_{F W_{N}}\right)$

$E_{B W}=\frac{\Delta t}{3}\left(P_{B W_{0}}+4 P_{B W_{1}}+2 P_{B W_{2}}+4 P_{B W_{3}}+2 P_{B W_{4}}+\cdots+2 P_{B W_{N-1}}+4 P_{B W_{N-1}}+\right.$

$\left.P_{B W_{N}}\right)$

$\Delta t=$ compute step or step size and is expressed as

$$
\Delta t=\frac{t_{m}-t_{d}}{N}
$$

$\mathrm{N}=$ total number of sampling instant.

The protection principle presented in this paper is based on Equations (2.17) and (2.18) respectively.

\section{The Protection Principle}

Consider the schematic diagram shown in Figure 3.1. The inductors, $L$ shown are representative of di/dt limiting inductors as per HVDC circuit breaker or fault current limiters (FCL) [3]. 


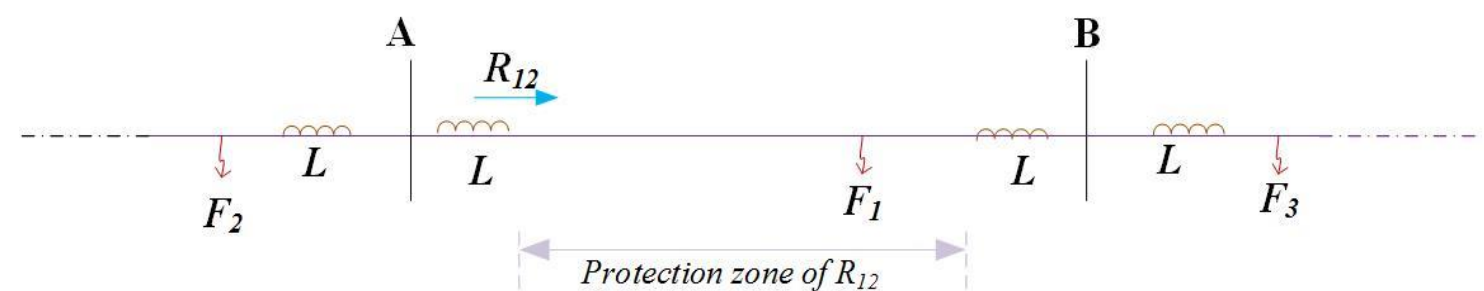

Fig. 3.1 Fault propagation across a transmission network

As shown, with respect to relay $R_{12}, F_{1}$ and $F_{3}$ are forward fault whereas $F_{2}$ is a reverse fault. Also, $F_{1}$ is an internal fault whilst $F_{2}$ and $F_{3}$ are external fault. Therefore, $F_{1}$ and $F_{3}$ are forward internal and forward external fault, FIF and FEF respectively.

\subsection{Conditions for Forward and Reverse faults}

Considering Figure 3.2, when $v_{B A}$ from fault $F_{1}$ reaches the relay terminals (say terminal $A$ ), a new wave, $v_{F A}$ is reflected. In practice, the reflected waves at a boundary has lower magnitude compared with the magnitude of the incident wave.

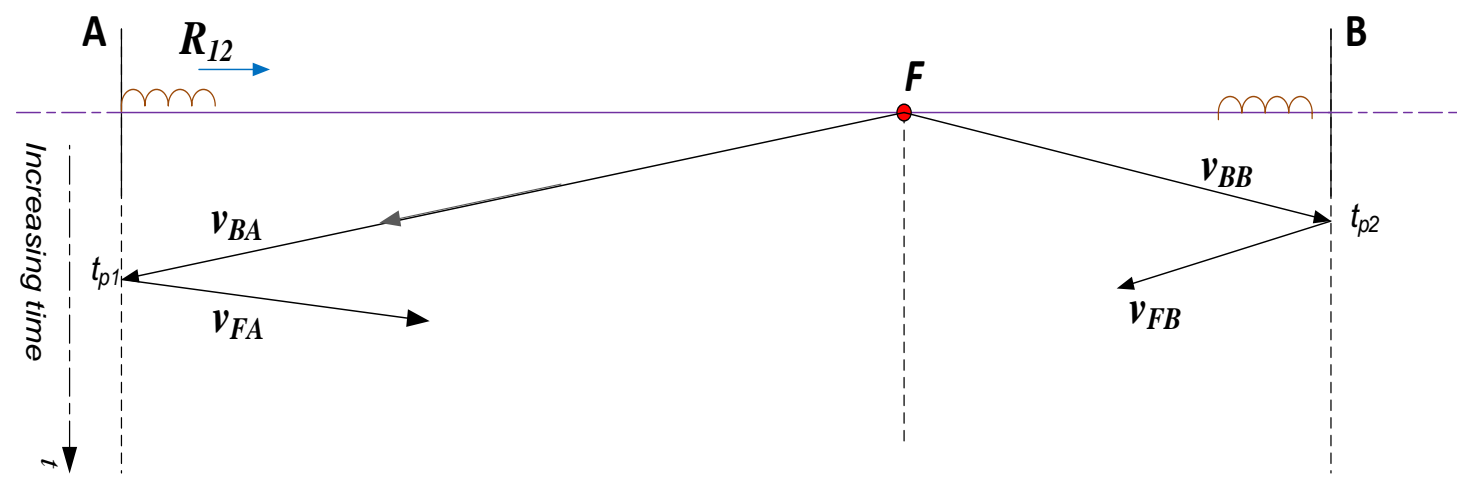

Fig. 3.2 Condition for forward fault

Hence $v_{F A}$ is less than $v_{B A}$ for a specified short period of time following fault inception. Therefore,

$$
v_{F A}<v_{B A} \text { or } \frac{v_{F A}}{v_{B A}}<1
$$

Therefore, from Equations (2.13) - (2.15), 


$$
\frac{E_{F W}}{E_{B W}}<1
$$

Now considering Figure 3.3, and with a fault $F_{2}$, the first wave seen by $R_{12}$ is $V_{F A}$.

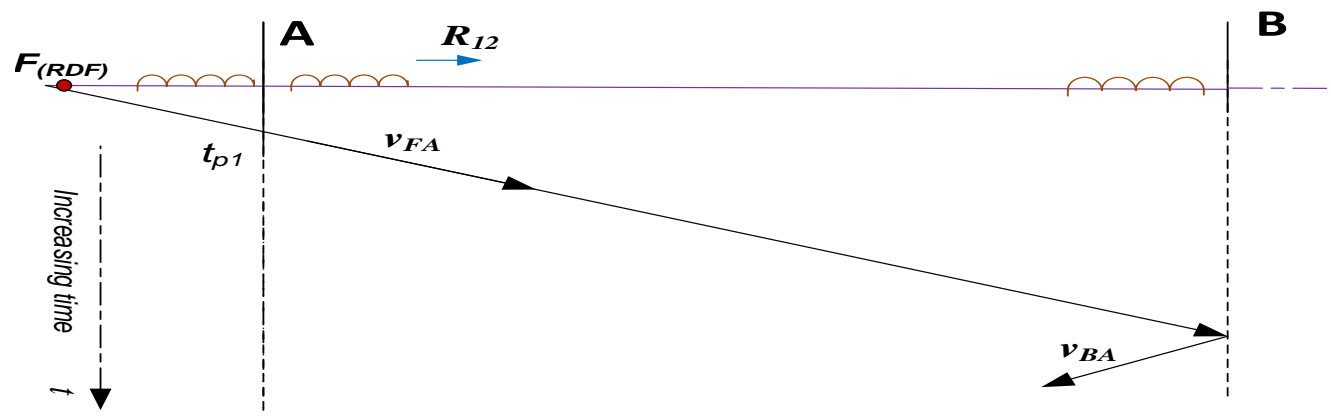

Fig. 3.3 Condition for reverse fault

Therefore, for fault $F_{2}$, the magnitude of $v_{F A}$ is greater that $v_{B A}$, and we can write,

$$
v_{F A}>v_{B A} \quad \text { or } \quad \frac{v_{F A}}{v_{B A}}>1 ; \frac{E_{F W}}{E_{B W}}>1
$$

The fundamental principle is that, at the instant of arrival of the first incident wave at the relay terminal, $V_{B A}$ is developed before $V_{F A}$. Therefore, $E_{B W}$ develops before $E_{F W}$, making the ratio, $E_{F W} / E_{B W}$ to always be less than unity, and irrespective of the fault distance.

\subsection{Forward internal versus forward external faults}

In Figure 3.4, $R_{12}$ sees a much attenuated $v_{F A}$ and $v_{B A}$, hence a reduced magnitude of $E_{F W}$ and $E_{B W}$. This is largely due to the DC inductor located at each of the line ends, which provides attenuation to the high frequency components resulting from an external fault. However, the attenuation of a travelling wave due to $F I F$ such as $F_{1}$ in Figure 3.1, is much smaller. 


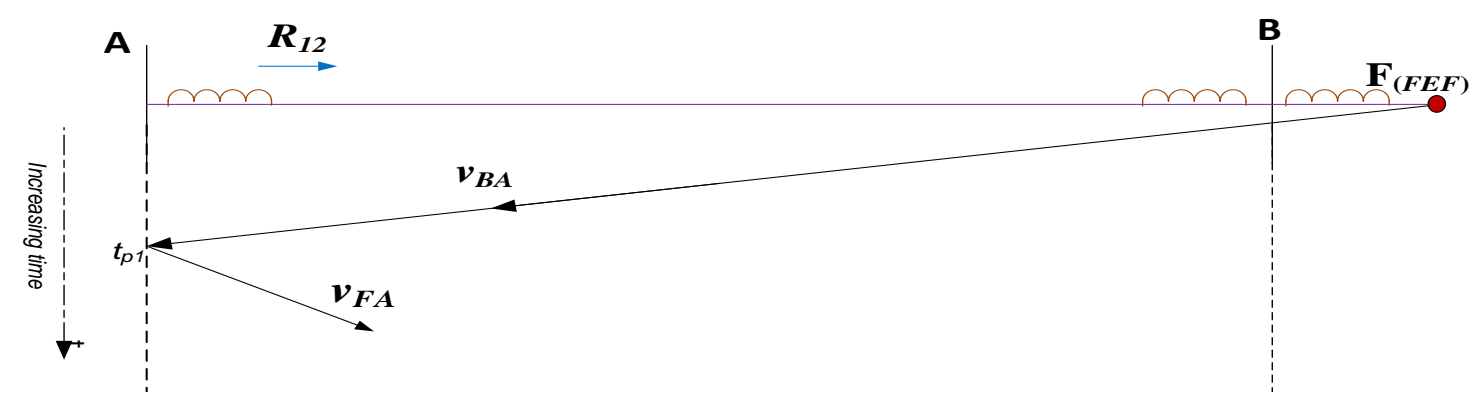

Fig. 3.4 Discriminative criterion ondition for forward internal versus forward external fault

In this paper, the discriminative criterion between a forward internal and forward external fault is due to the DC inductor located at the line ends. The inductor helps to provide attenuation for the high frequency contents of the fault generated signal resulting from a FEF Therefore, the magnitude of $E_{F W}$ and $E_{B W}$ for the case of FIF are larger than those for FEF. Hence, the magnitude of the energy in the travelling wave for FIF over a pre-set time duration is larger that that for FEF. Therefore,

$$
\begin{array}{ll}
\text { For FIF } & E_{F W}>E_{F W}(\text { set }) \\
& E_{B W}>E_{B W}(\text { set }) \\
\text { For FEF }, & E_{F W}<E_{F W}(\text { set }) \\
& E_{B W}<E_{B W}(\text { set })
\end{array}
$$

Generally, once the ratio criterion is satisfied indicating a forward directional fault, either the magnitude of $E_{F W}$ and $E_{B W}$ for a pre-set time following the occurrence of fault gives the condition for a FIF. However, to improve the security and reliability of the protection algorithm, this paper adopts both the positive and negative fault discriminative criteria.

The protection logic is therefore defined as follows 
- Positive fault discriminative criteria is given as:

$$
E_{F W}>E_{F W(s e t)} \text { OR } E_{B W}>E_{B W(s e t)} \quad \text { (Relay will operate) }
$$

- Negative fault discriminative criteria is given as:

$$
E_{F W}<E_{F W(s e t)} A N D \quad E_{B W}<E_{B W(s e t)} \text { (Relay will not operate) }
$$

\subsection{General Conditions for internal versus external fault}

For an internal fault to be declared in a section or branch of the DC grid, both the ratio criterion and the magnitude criterion must be met.

Thus

- $\frac{E_{F W}}{E_{B W}}<1$ (Ratio Criterion)

- $\quad E_{F W}>E_{F W(s e t)} O R E_{B W}>E_{B W(\text { set })}$ (Magnitude Criterion)

Where $E_{F W} / E_{B W}$ is the travelling wave power ratio

As will be seen later, the protection setting, $E_{F W(s e t)}$ and $E_{B W(s e t)}$ is arrived at by considering the most critical condition for the relay. The flow chart for the proposed TWBP scheme is shown in Figure 3.5, where $P_{s t}$ is the threshold for the starting unit. As shown, following the detection of transient by the starting unit, the instantaneous DC voltage and DC current, $v_{D C}[n]$ and $i_{D C}[n]$ respectively are sampled based on a three point moving average filter to obtain the average DC voltages and current, $v_{D C(A V)}[n]$ and $i_{D C(A V)}[n]$ respectively. This was done to reduce or minimise the effect of any spike resulting from the fault generated transient. Generally, for practical applications, the effect of noise will impact on the accuracy of the relay signal and therefore some form of advanced filtering may be required. However, this study assumes the idealised case of a perfect signal which is representative of the trend in the travelling wave components $\left(P_{F W}\right.$ and $\left.P_{B W}\right)$. 


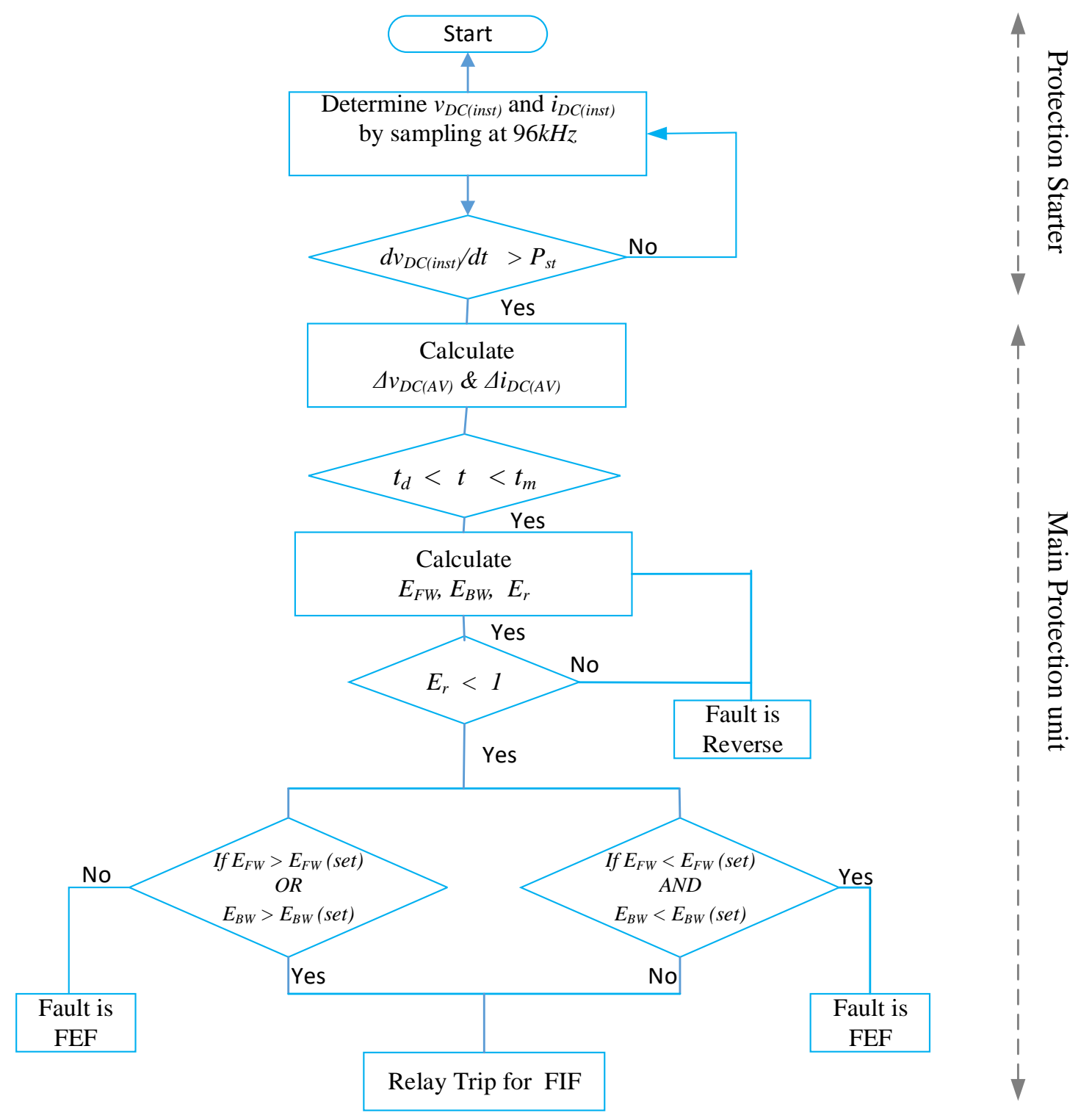

Fig. 3.5 The flow chart of the proposed TWBP scheme

In this paper, the pre-fault values are the steady state $D C$ voltages and current ( $V_{D C \text { (inst) }}$ and $V_{D C \text { (inst) }}$ respectively) observed at the relay terminal during normal operating conditions. These values were continuously sampled and monitored until a sudden change in the voltage and current is detected. This will also be the case for practical applications. During pre-fault conditions, $\Delta v_{D C}$ and $\Delta v_{D C}$ are ideally zero, and also from Equations (2.13) - (2.15), $E_{F W}$ and $E_{B W}$ are zero. 
As per IEC guidelines for DC protection [30], the sampling frequency, $f_{s}$ used in this paper was $96 \mathrm{kHz}$. A window length $t_{W}$, of $500 \mu \mathrm{s}$ was assumed. This was found to provide sufficient samples for the relay decision. Since $f_{s}=96 \mathrm{kHz}$, sampling period

$$
T_{s}=\frac{1}{96 k H z}=10.42 \mu s
$$

The total number of samples for relay decision,

$$
N=\frac{t_{W}}{T_{S}}=\frac{500 \mu s}{10.42 \mu} \approx 48 \text { samples }
$$

\section{Validations}

To validate the proposed protection technique, simulations were carried out as shown in Figure 4.1, and with arbitrary fault locations and fault resistances, $R_{f}$. The test model consists of a 4 terminal Modular Multi-level Converter (MMC) based DC grid made available in PSCAD/EMTDC software as per CIGRE 4-terminal test model [31]. As shown, the network consists of 4 cable sections and four modular multi-level converter (MMC) based on half-bridge submodule configuration. Generally, MMC can either be of half bridge and full bridge submodule arrangements. However, details of $M M C$ configurations and topologies are outside the scope of this paper but are available in literature [32-33]. Furthermore, the effects of the converter operation on the proposed protection principle were not studied in this paper as the goal is to detect a DC side fault on the DC link.

As shown, MMC1, MMC2 and MMC3 are connected to an AC source whilst $M M C 4$ is connected to a fixed load. Under steady state condition, MMC1 and MMC3 operate as rectifiers and as such imports power from the AC side whilst MMC2 and MMC4 operates as inverters exporting power to the load and AC grid respectively. Details of the converter and AC parameters including the load parameter are given in Appendix 
1. The cables are of frequency dependent distributed parameter models and as such, the wave effects including attenuation, losses and distortion have been accounted for. All cable sections were assumed to have a length of $200 \mathrm{~km}$. Details of the cable parameters as well as the configuration are given Appendix 2. Air cored inductors of $1 \mathrm{mH}$ were placed at the $\mathrm{DC}$ cable ends to represent the inductive effects of HVDC breakers or fault current limiters. These inductors also helps to limit the rate of rise of current during short circuits. All fault scenarios were applied at $2 s e c$ from the start of the simulation.

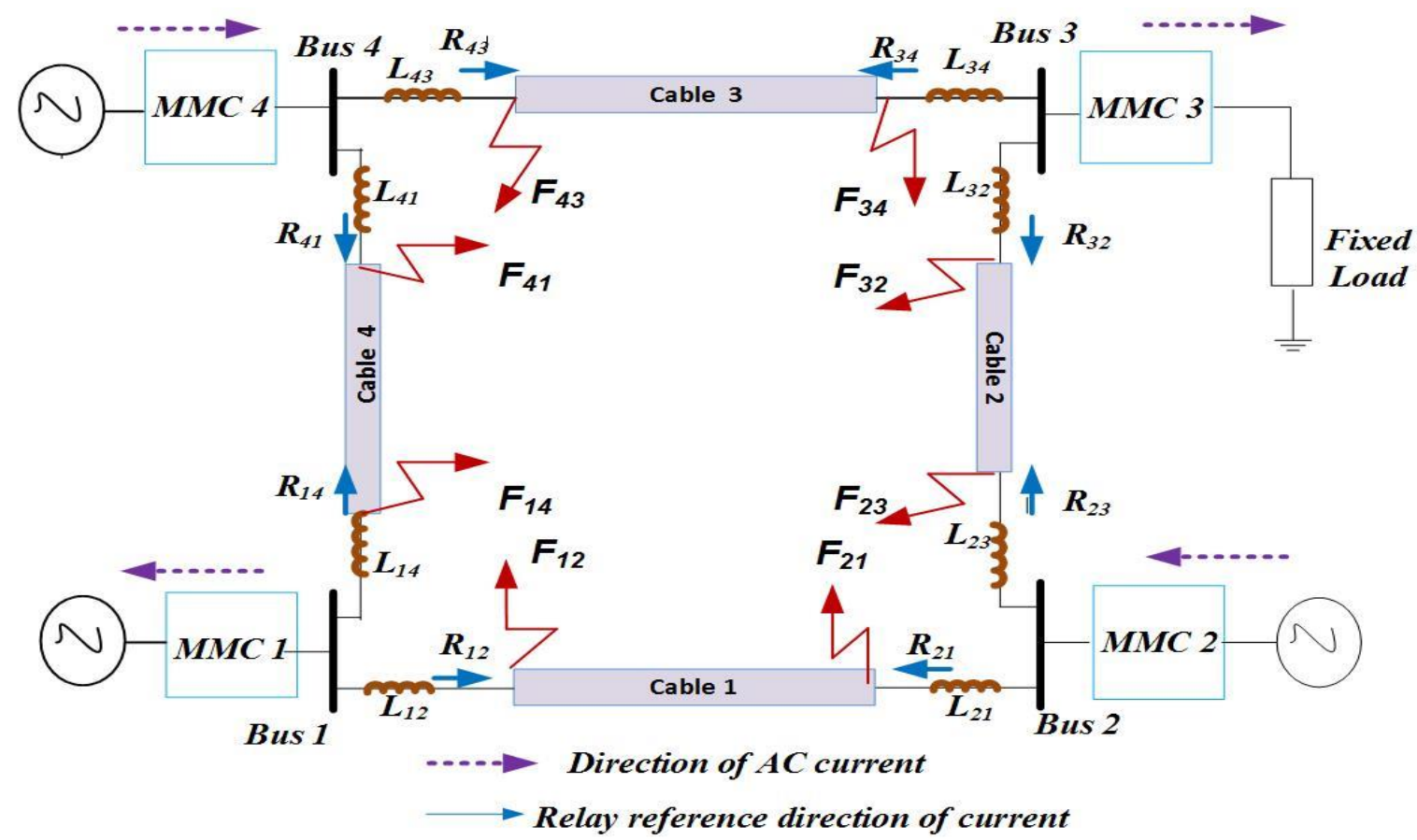

Fig. 4.1. Four terminal DC grid

In this study, the most critical condition for the relay was used as a basis to carry out the simulation. In the scenario shown in Figure 4.1, and considering $R_{12}$ in the first instance, this is a high resistance remote internal fault $\left(F_{21}=500 \Omega\right)$ against a low resistance forward external fault and reverse faults respectively $\left(F_{23}=0.01 \Omega \& F_{14}=\right.$ $0.01 \Omega)$ 


\subsection{Simulation Results}

The simulation results showing the DC currents and voltages at the respective relay terminals considering a P-G fault occurring at $F_{21}$ with respect to relay $R_{12}$ are shown in Figures 4.1 and 4.2 respectively. All measurements were take from the positive pole terminal of the DC link. As shown in Figure 4.1, the direction of flow of the DC currents in the respective relays indicated during the steady state are consistent with the state of the respective converters during pre-fault operations; where those located at the inverting MMCs (MMC2 and MMC4) have negative polarity whilst those located at a rectifying MMCs (MMC1 and $M M C 3)$ has positive polarity. Furthermore, their respective magnitudes and rate of rise are determined by the distance between the relay location and the point of fault. These include the parasitic inductance of the cable, the cable resistance, and fault resistance as well as the DC link inductance. Generally, the closer the relay is to the point of fault, the larger the magnitudes of the current during faults.

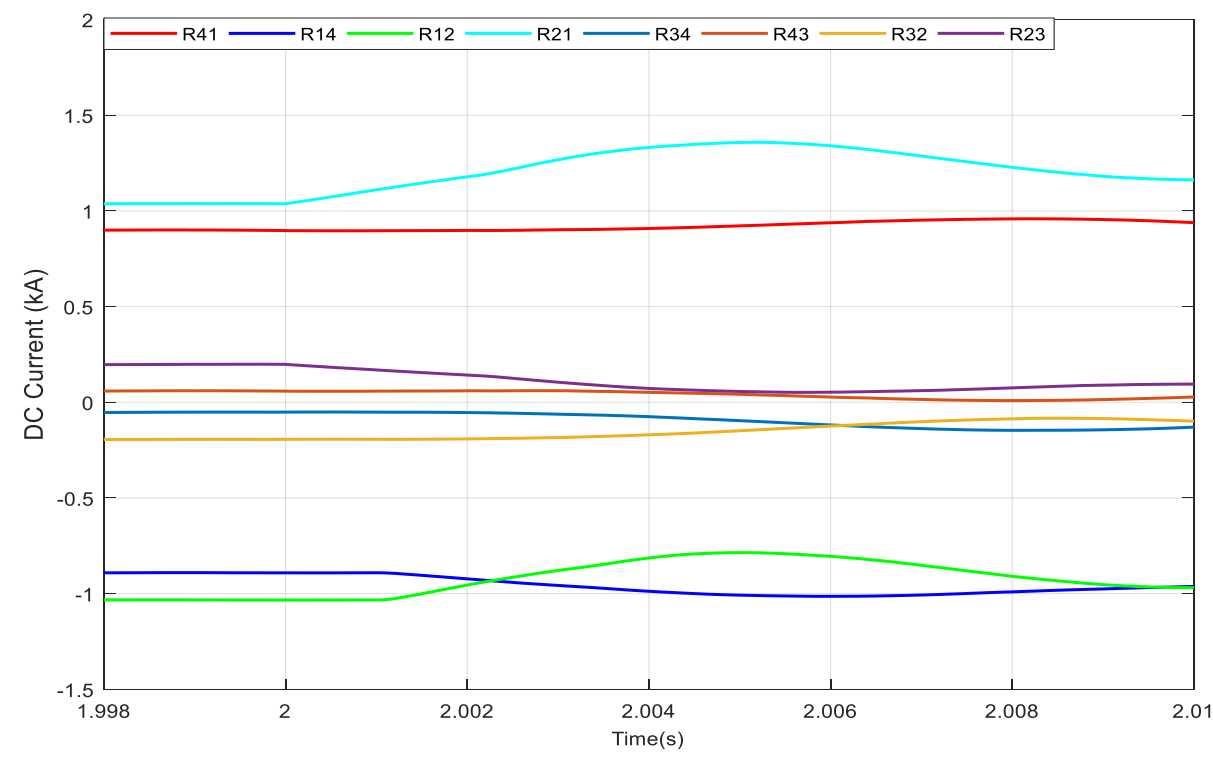

Fig. 4.2 DC current showing per-fault and post fault conditions for a forward fault. $\left(t_{\text {fault }}=2 s\right)$

The DC voltage waveforms is shown in Figure 4.3, where their magnitude following the fault is dependent on the short circuit as well as the apparent impedance from the 
infeeds [9]. Also, each relay terminal experiences a different DC voltage gradient which is largely dependent on varying fault path impedance resulting from to the distance between the fault and measurement points in the network [9]

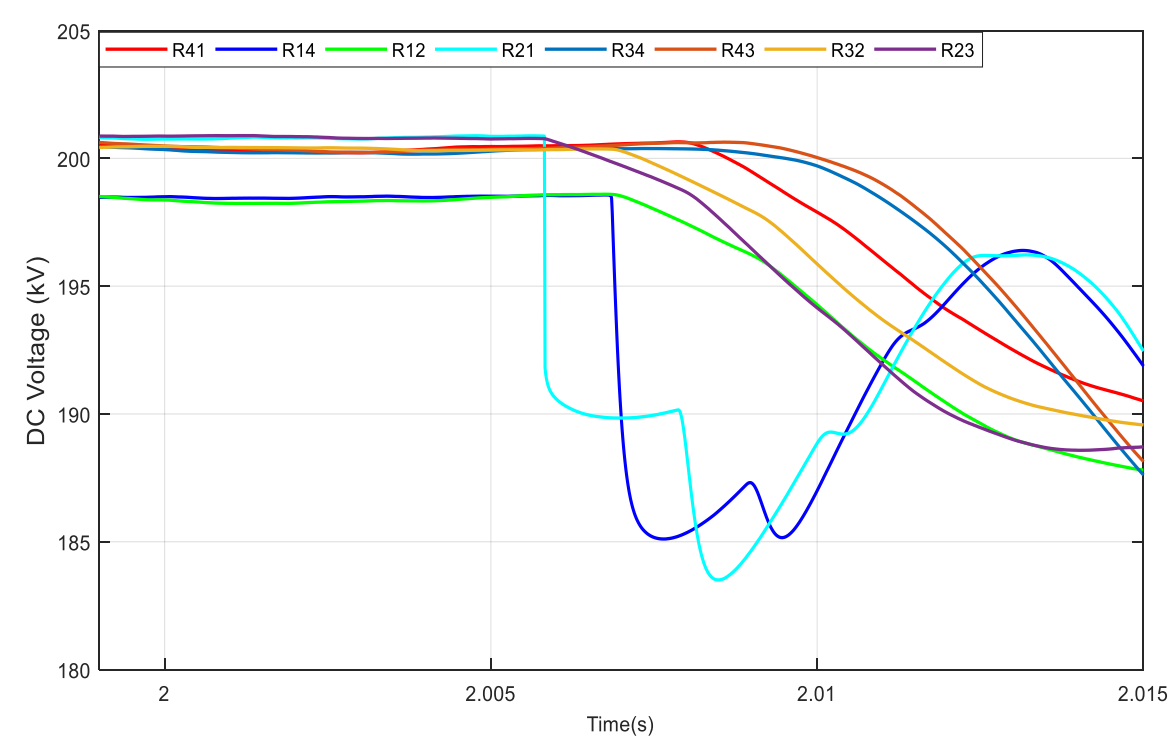

Fig. 4.3 DC voltage showing per-fault and post fault conditions for a forward fault. $\left(t_{\text {fault }}=2 s\right)$

Considering relay $\mathrm{R}_{12}$, the calculated travelling wave power components, $P_{F W}$ and $P_{B W}$ respectively are shown in Figure 4.4. As shown, under steady state conditions, $P_{F W}$ and $P_{B W}$ are zero indicating that no travelling waves are present. Therefore, $E_{F W}$ and $E_{B W}$ respectively will also be ideally zero. However, at the instant of fault inception (after 2s), travelling waves are generated and propagate along the cables and as such power $E_{F W}$ and $E_{B W}$ are developed by the travelling waves. Generally, a significant of time will elapse (depending on the distance between the relay terminal and the fault) until the travelling wave component arrives at the relay terminal. In this scenario shown, the arrival time of the travelling wave at $R_{12}$ due to fault $F_{21}$ is 2.00102 s while that for $F_{23}$ and $F_{14}$ are $2.00112 \mathrm{~s}$ and 2.0005 s respectively. This is not a major issue because as far as the relay is concerned, the arrival time of the first incident wave at its terminal is taken as $t_{d}$. As shown in Figure $5 \mathrm{a}$, the magnitude of $P_{B W}$ recorded at the relay terminals during the first few milliseconds following the arrival of the first 
incident wave exceeds that of $P_{F W}$ indicating that fault $F_{21}$, is a forward fault with respect to relay $R_{12}$.

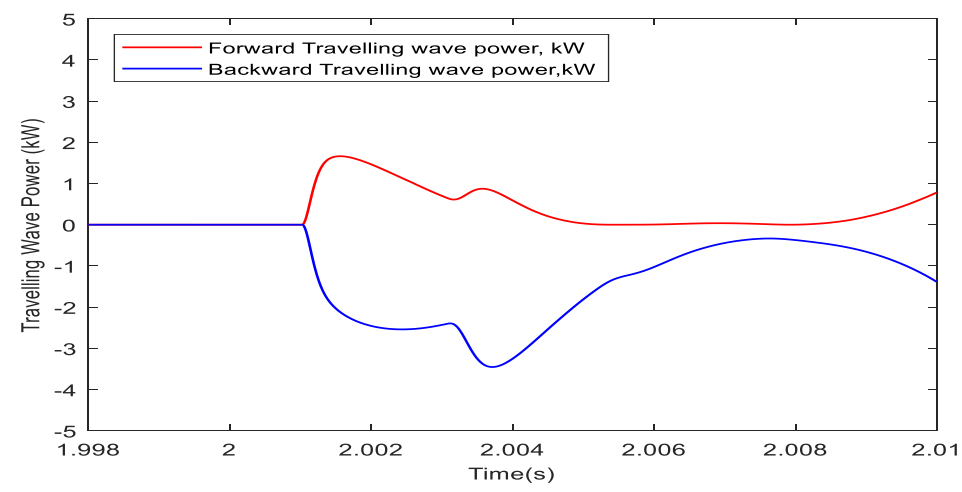

(a)

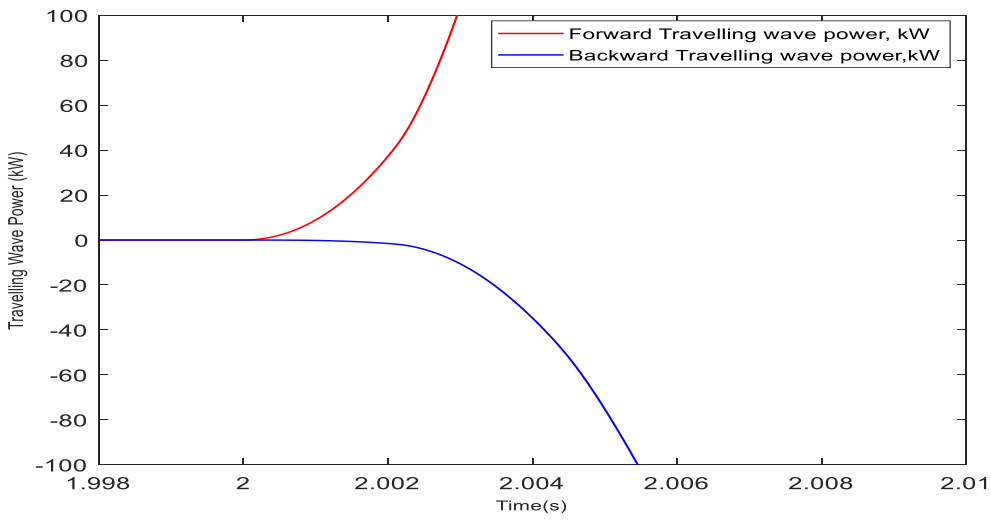

(b)

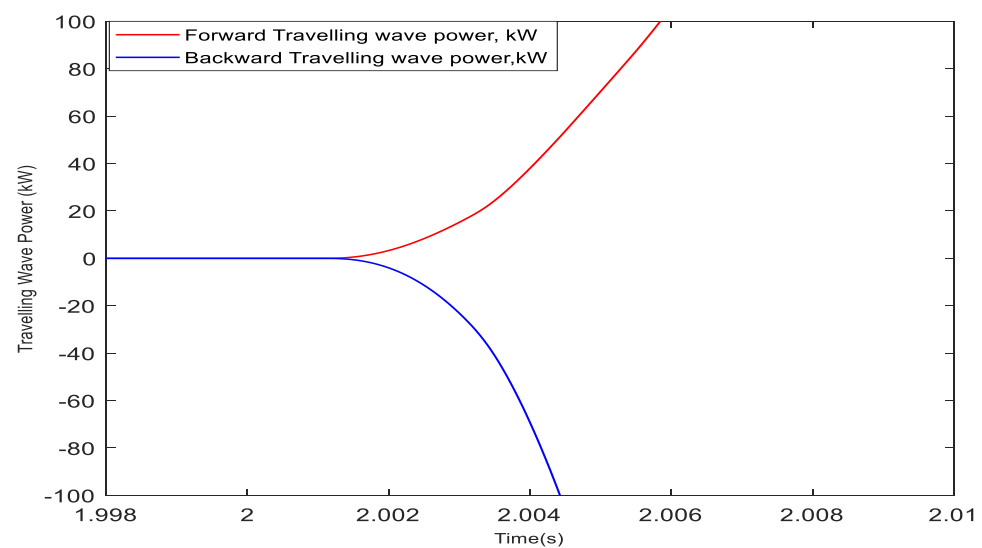

(c)

Fig. 4.4 Calculated travelling wave power with respect to Relay $R_{21}$

(a) Forward internal fault (FIF), $F_{21}$

(b) Reverse fault, $F_{14}$

(c)Forward external fault (FEF), $F_{23}$ 
Therefore, the ratio $E_{F W} / E_{B W}$ during the measurement period will be less than unity. However, in Figure 5b, the magnitude of $P_{F W}$ exceeds that of $P_{B W}$ during the measurement period indicating that $F_{14}$ is a reverse fault with respect to relay $R_{12}$, and therefore the ratio $E_{F W} / E_{B W}$ will be greater than unity. It can be seen in Figure $6 \mathrm{c}$ that although the magnitude of $P_{B W}$ exceeds that of $P_{F W}$ (therefore $E_{F W}$ will exceed $E_{F W}$ ), indicating that $F_{23}$ is a forward directional fault with respect to relay $R_{12}$, however the magnitudes of the travelling wave power components will be greater than unity. It can be seen in Figure 5c that although the magnitude of $P_{B W}$ and $P_{F W}$ in this case is significantly reduced compare to those in Figure 5a. This is because the high frequency components of the fault generated transient components are attenuated at the boundary consisting of busbar 2 , inductor $L_{21}$ and $L_{23}$ respectively.

Further studies were carried out considering both pole-to-pole $(P-G)$ and pole-ground $(P-P)$ faults. The calculated travelling wave power components, $P_{F W}$ and $P_{B W}$ are shown on an expanded scale in Figure 4.5. The subscripts "int" and "ext" indicates internal and external respectively.

The calculated values of $E_{F W}$ and $E_{B W}$ over a time window of $500 \mu s$ following the detection of the first incident wave at the relay terminal $\left(t=t_{d}\right)$ are given in Table 1. Generally, the magnitude of the travelling wave power components for a $P$-P fault is larger than that for a $P-G$ faults due to the ground fault resistance. The characteristic differences between a $P-G$ and a $P-P$ fault for a symmetrical monopole MMC have been well researched in [2][4]. This is not a major issue as the goal is to detect a DC link fault.

\subsection{The protection threshold}

In this paper, the protection threshold was arrived at by considering the most critical condition for the relay following the occurrence of fault. Ideally, this will be the 
maximum magnitude of the relay signal for an internal fault $\left(R_{f}=500 \Omega\right.$ in this study) against the minimum value for external fault $\left(R_{f}=0.01 \Omega\right.$ in this study). For example, considering relay $R_{12}$, this corresponds to $F_{21}=500 \Omega$ versus $F_{23}=0.01 \Omega$. The same holds for all other local relays indicated in Figure 4.1 Generally, after $500 \mu$ s and no fault is declared, the protection system is reset, until it is triggered again following the detection of any transient by the starting unit. In this paper, a protection threshold of $E_{F W}=4 \times 10^{-3} \mathrm{~kJ}$ and $E_{B W}=5 \times 10^{-3} \mathrm{~kJ}$ was used for the sake of convenience and considering the most critical conditions for all local relays indicated in Figure 4.1

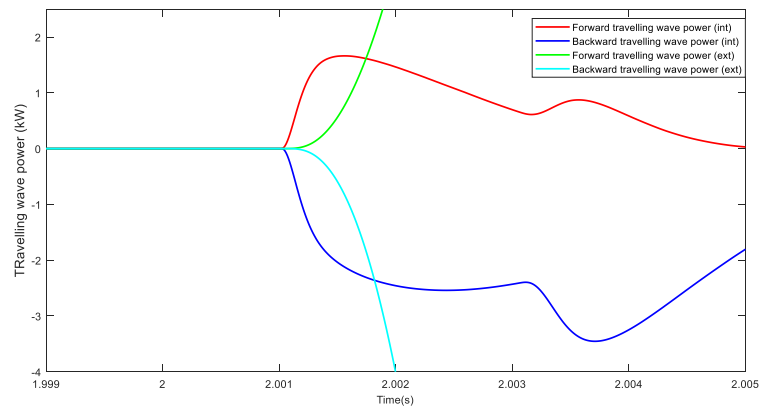

(a)

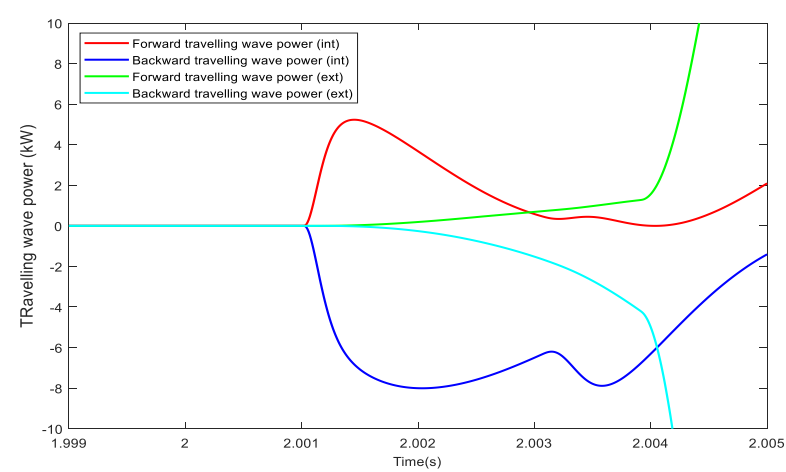

(b)

Fig. 4.5 Expanded scale of the calculated travelling wave power

(a) Forward and backward travelling wave power $(P-G)$,

(b) Forward and backward travelling wave power $(P-G)$ 
Table 1 Calculated traveling wave energy of Figure 6

\begin{tabular}{cccc} 
Fault type & $\left|E_{F W}\right|(\mathbf{k J})$ & $\left|E_{B W}\right|(\mathbf{k J})$ & $\left|E_{F W}\right| /\left|E_{B W}\right|$ \\
\hline$F I F_{(R f=500 \Omega) P-P}$ & $4.3 e-4$ & $5.3 e-3$ & 0.89 \\
$F E F_{(R f=0.01 \Omega) P-P}$ & $1.12 e-4$ & $1.17 e-4$ & 0.95 \\
$F I F_{(R f=500 \Omega) ~ P-G}$ & $1.5 e-3$ & $2.0 e-3$ & 0.84 \\
$F E F_{(R f=0.01 \Omega) P-G}$ & $1.1 e-5$ & $1.2 e-5$ & 0.94 \\
\hline & $F I F:$ Forward internal fault & $F E F:$ Forward external fault
\end{tabular}

\subsection{The starting unit.}

To ensure that the protection scheme remain stable during normal operating conditions, a protection starter was incorporated into the protection scheme. The protection starter used in this scheme is a $d v / d t$ element. Once the threshold $\left(P_{s t}\right)$ set for the starting element is exceeded, the main protection system is triggered into operation. In this paper, a $d v / d t$ of $1 \mathrm{~V} / \mu s$ was taken as the threshold for the starting element.

Since all cable sections are assumed to be the same length $(=200 \mathrm{~km})$ in this study, this value was consistent for all local relays indicated. This value was arrived at by considering a FEF occurring at remote end of an adjacent feeder with respect to a local relay. For example, with respect to relay $R_{12}$ on Figure 4.1 , this will be a fault $F_{32}$ occurring cable section 2 as shown. Generally, this will vary depending on the total length of the cable section

\subsection{Sensitivity studies}

To further investigate the suitability of the proposed protection scheme, simulation was also carried out considering all fault scenarios indicated in Figure 5. In all cases, both $P-G$ and $P-P$ were considered. The simulation results presented in Tables 2 and 3 for P-G and P-P faults show consistency with the conditions in section 3.3 as per 
conditions for FIF versus FEF, as well as the protection threshold given in section 4.2. In all cases $E_{R}$ is less than unity, indicating a forward directional fault. Furthermore, the magnitude of $E_{F W}$ and $E_{B W}$ for during the measurement period for FIF exceeded those for FEF for P-G.

As can be seen in Tables 2 and 3, the calculated $E_{F W}$ and $E_{B W}$ are consistent for each of $P-G$ and $P-P$ faults, and irrespective of the steady state load current. This implies that the travelling wave components arriving at the relay terminal is largely dependent on the pre-fault steady state voltage as well as the fault resistance and less affected by the source parameters. Therefore, the relay settings can be done off site, provided that the parameters of the cables are known. In all cases, a protection setting of $E_{F W}$ $=4 \times 10^{-3} \mathrm{~kJ}$ and $E_{B W}=5 \times 10^{-3} \mathrm{~kJ}$ would provide discrimination between a FIF and FEF

Table 2 Calculated travelling wave energy components (Pole-ground fault)

\begin{tabular}{|c|c|c|c|c|c|c|}
\hline $\begin{array}{l}\text { Local } \\
\text { relay }\end{array}$ & $\begin{array}{c}\text { Fault } \\
\text { Location }\end{array}$ & $\begin{array}{l}\text { Fault type } \\
\text { with respect to local relay }\end{array}$ & $\begin{array}{c}\text { Fault } \\
\text { Resistance( }(\Omega)\end{array}$ & $\begin{array}{c}\left|E_{F W}\right| \\
(k J)\end{array}$ & $\begin{array}{c}\left|E_{B W}\right| \\
(k J)\end{array}$ & $\left|E_{F W}\right| /\left|E_{B W}\right|$ \\
\hline \multirow[t]{2}{*}{$R_{12}$} & $F_{21}$ & $F I F$ & 500 & $4.3 e-4$ & $5.3 e-3$ & 0.89 \\
\hline & $F_{23}$ & $F E F$ & 0.01 & $1.12 e-4$ & $1.17 e-4$ & 0.95 \\
\hline \multirow[t]{2}{*}{$R_{21}$} & $F_{12}$ & $F I F$ & 500 & $5.12 e-4$ & $5.7 e-4$ & 0.89 \\
\hline & $F_{14}$ & $F E F$ & 0.01 & $1.55 e-4$ & $1.62 e-4$ & 0.91 \\
\hline \multirow[t]{2}{*}{$R_{23}$} & $F_{32}$ & $F I F$ & 500 & $5.2 e-4$ & $5.9 e-4$ & 0.88 \\
\hline & $F_{34}$ & $F E F$ & 0.01 & $2.1 e-4$ & $2.3 e-4$ & 0.92 \\
\hline \multirow[t]{2}{*}{$R_{32}$} & $F_{23}$ & $F I F$ & 500 & $5.38 e-4$ & $6.12 e-4$ & 0.88 \\
\hline & $F_{21}$ & $F E F$ & 0.01 & $1.41 e-4$ & $1.57 e-4$ & 0.90 \\
\hline \multirow[t]{2}{*}{$R_{34}$} & $F_{43}$ & $F I F$ & 500 & $5.51 e-4$ & $6.1 e-4$ & 0.90 \\
\hline & $F_{41}$ & $F E F$ & 0.01 & $1.2 e 4$ & $1.4 e-4$ & 0.85 \\
\hline \multirow[t]{2}{*}{$R_{43}$} & $F_{34}$ & $F I F$ & 500 & $5.52 e-4$ & $6.3 e-4$ & 0.87 \\
\hline & $F_{32}$ & $F E F$ & 0.01 & $1.22 e 4$ & $1.47 e-4$ & 0.83 \\
\hline \multirow[t]{2}{*}{$R_{41}$} & $F_{21}$ & $F I F$ & 500 & $5.53 e-4$ & $6.1 e-4$ & 0.90 \\
\hline & $F_{23}$ & $F E F$ & 0.01 & $1.2 e 4$ & $1.4 e-4$ & 0.86 \\
\hline \multirow[t]{2}{*}{$R_{14}$} & $F_{41}$ & $F I F$ & 500 & $7.5 e-4$ & $8.1 e-4$ & 0.92 \\
\hline & $F_{43}$ & $F E F$ & 0.01 & $1.2 e-4$ & $1.4 e-4$ & 0.85 \\
\hline
\end{tabular}


FIF: Forward internal fault; $\quad$ FEF: Forward external fault

Note: In Figure 4.1, with respect to relay $R_{12}$, the critical condition is fault $F_{21}$ with large fault resistance $\left(R_{f}=500 \Omega\right)$ against fault $F_{23}$ with low fault resistance $\left(R_{f}=0.01 \Omega\right)$. The same holds for all other relays indicated

Generally, once a DC cable fault is declared, the decision of whether it is a $P$-G or $P$ $P$ fault can be arrived at by considering the polarities of the positive and negative pole voltages and current respectively as in [2][4]. For a P-G fault, the positive pole voltages collapse suddenly whilst the negative pole voltages increase to approximately $2 p u$. However, in a $P$-P fault, both the positive and negative pole voltages reduce to zero, depending on the fault resistance.

Table 3 Calculated travelling wave energy components (Pole-Pole fault)

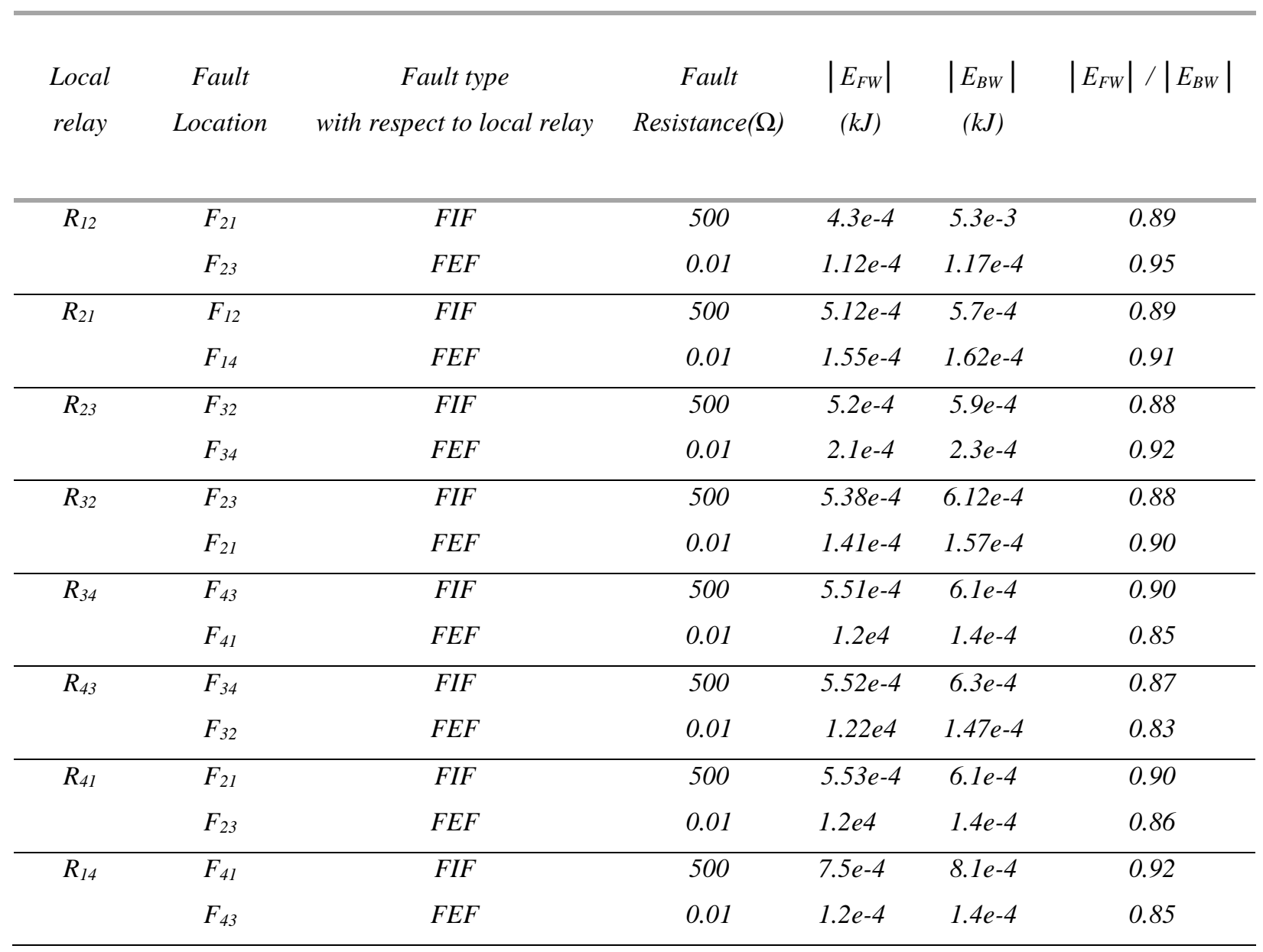

FIF: Forward internal fault; $\quad$ FEF: Forward external fault 
Note: In Figure 4, with respect to relay $R_{12}$, the critical condition is fault $F_{21}$ with large fault resistance $\left(R_{f}=500 \Omega\right)$ against fault $F_{23}$ with low fault resistance $\left(R_{f}=0.01 \Omega\right)$. The same holds for all other relays indicated

\subsection{Effect of sampling frequency}

For this purpose, a sampling frequency of $1 \mathrm{MHz}$ respectively was chosen. However, the choice is also of affected by cost of the commercially available relay, and therefore a compromise must be reached considering security and cost. For example, for a sampling frequency of $1 \mathrm{MHz}$ in this scenario and considering relay $R_{12}$, the calculated forward and backward travelling wave energy ( $E_{F W}$ and $E_{B W}$ respectively) was $3.3 e-5$ and $1.6 \mathrm{e}-5$ for internal fault (FIF) and $7.64 \mathrm{e}-7$ and $1.70 \mathrm{e}-6$ for external fault (FEF). From implementation standpoint, study shall continue as in [36-37], however, the analysis carried out in this study are based on simulations.

\subsection{Effect of Noise}

To investigate the effect of noise on the proposed algorithm, a Gaussian (white) noise of varying degrees of signal-noise ratios (SNRs): $50 \mathrm{~dB}, 40 \mathrm{~dB} 30 \mathrm{~dB}, 25 \mathrm{~dB}$ respectively; were introduced into the DC current and voltage waveforms (Figure $4.6-4.9$ )
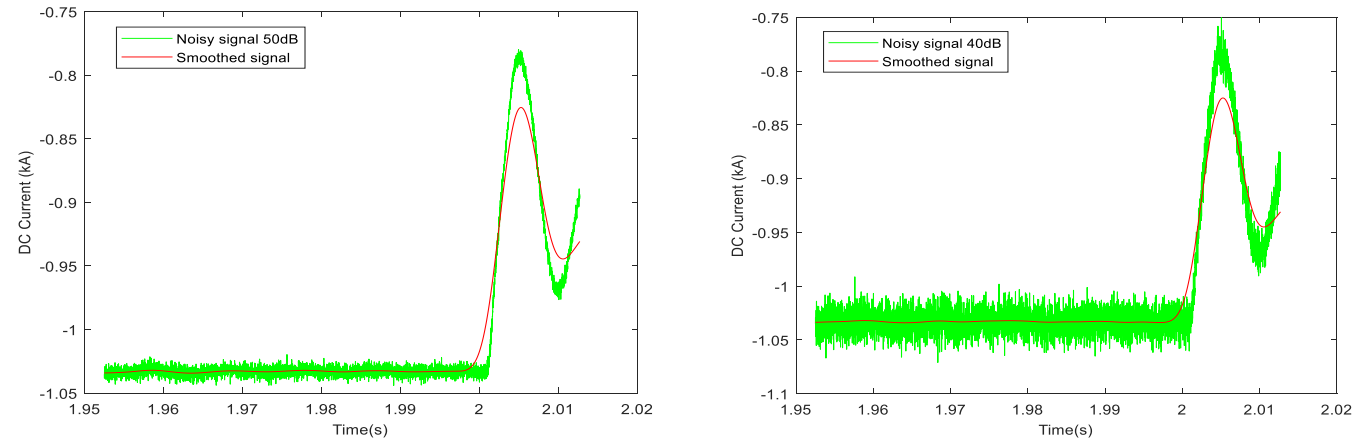

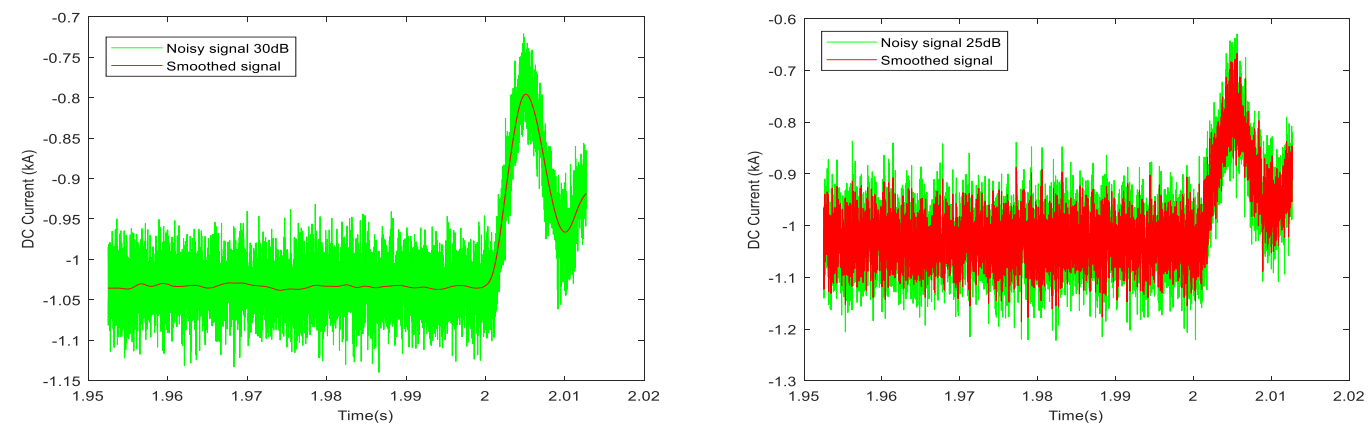

Fig. 4.6 Noisy and Smoothed Current Waveform measured at the relay R12, with signal to noise ratios for internal fault: (a) $50 \mathrm{~dB}$; (b) $40 \mathrm{~dB}$ (c)30dB (d)25dB

This was assumed to simulate a noisy signal in this study. Thereafter a Gaussian filter was used to extract the actual DC voltage and current signal from the actual measured quantities contaminated by the noise. However, at a SNR of less than $30 \mathrm{~dB}$, the effect of the noise predominates, in the current waveforms even after applying a filter; whilst the critical point for the case of the voltage waveform was found to be $40 \mathrm{~dB}$. This implies that the voltage waveforms are more susceptible to noise than the current waveform. However, as shown the effect of the noise is larger in the case of the internal faults than the external faults. This is because the higher frequency contents of the fault superimposed current and voltage components are attenuated at the discontinuities for the case of external faults.
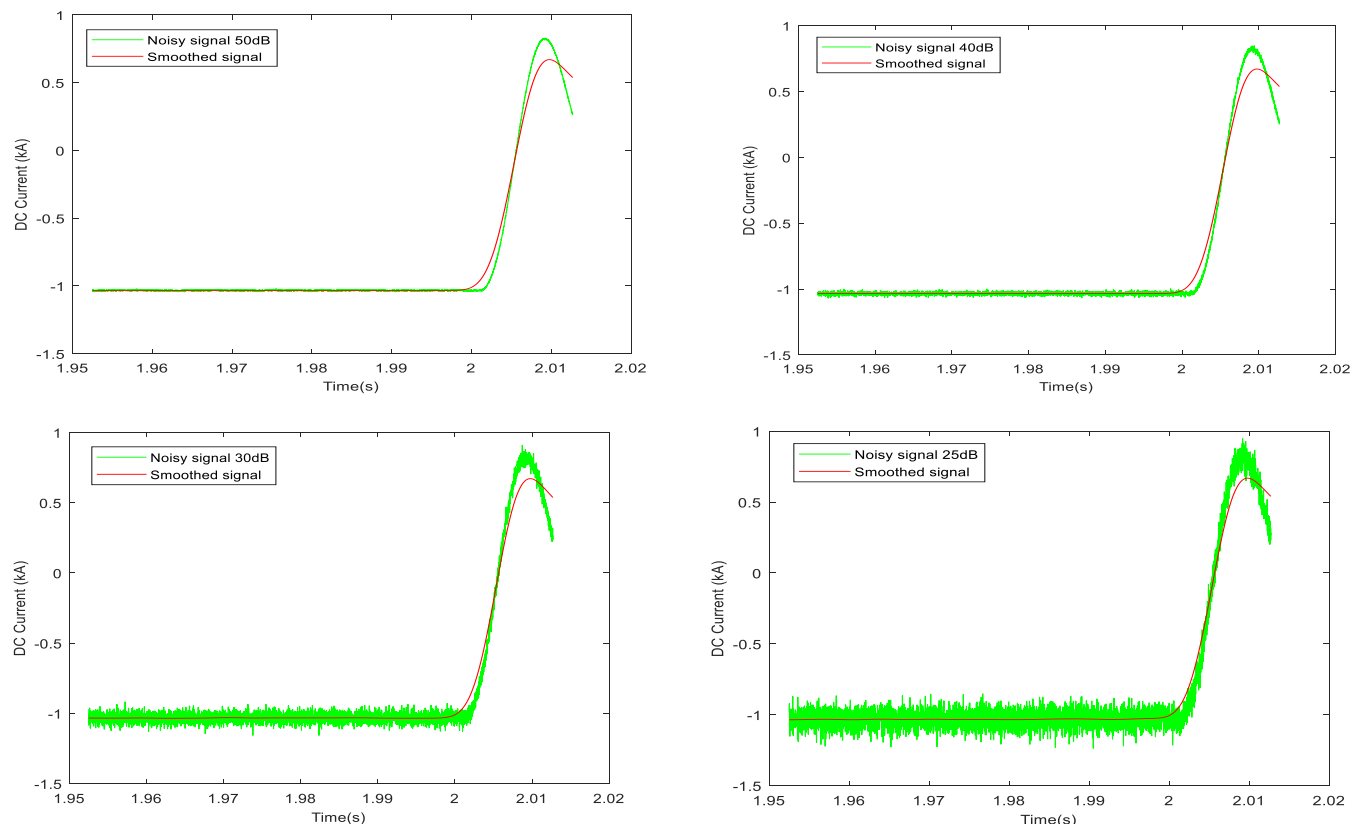
Fig. 4.7 Noisy and Smoothed Current Waveform measured at the relay R12, with signal to noise ratios for external fault: (a) $50 \mathrm{~dB}$; (b) $40 \mathrm{~dB}$ (c)30dB (d)25dB

The study shows a significant reduction in the noise by the application of the Gaussian filter which is representative of a low pass filtering; but with a slight reduction in the peaks and width of the smoothed signal as shown. Generally, noise associated with travelling waves are of varying degrees of frequencies, therefore further studies is proposed to investigate. Studies in this regard has been documented in [38-40]
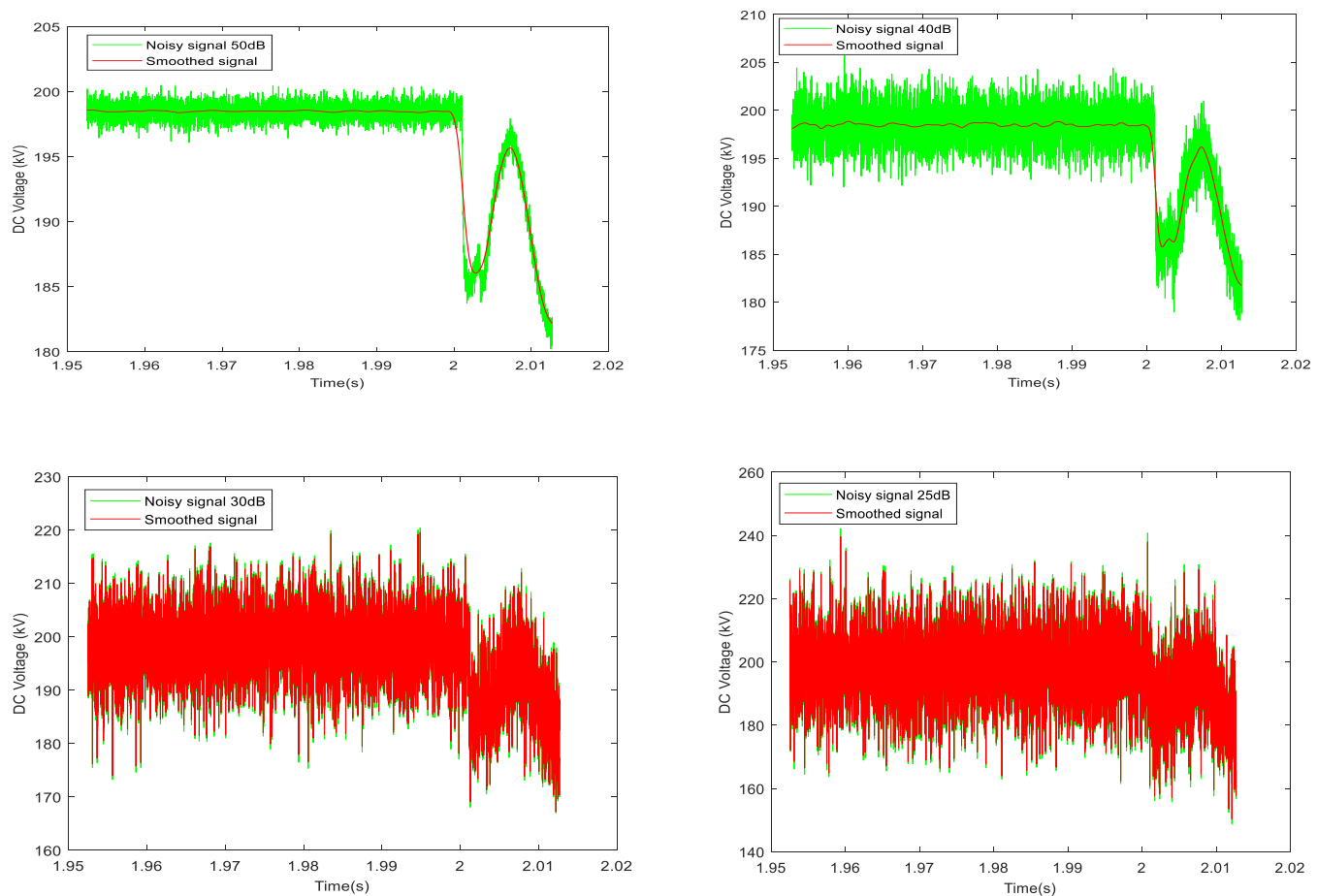

Fig. 4.8 Noisy and Smoothed voltage Waveform measured at the relay $R 12$, with signal to noise ratios for internal fault: (a) $50 \mathrm{~dB}$; (b) $40 \mathrm{~dB}$ (c)30dB (d)25dB
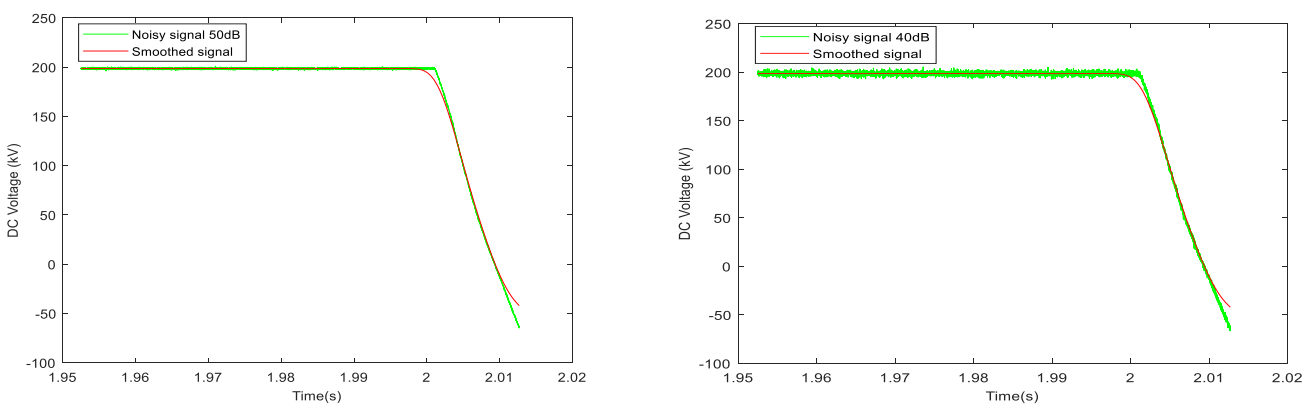

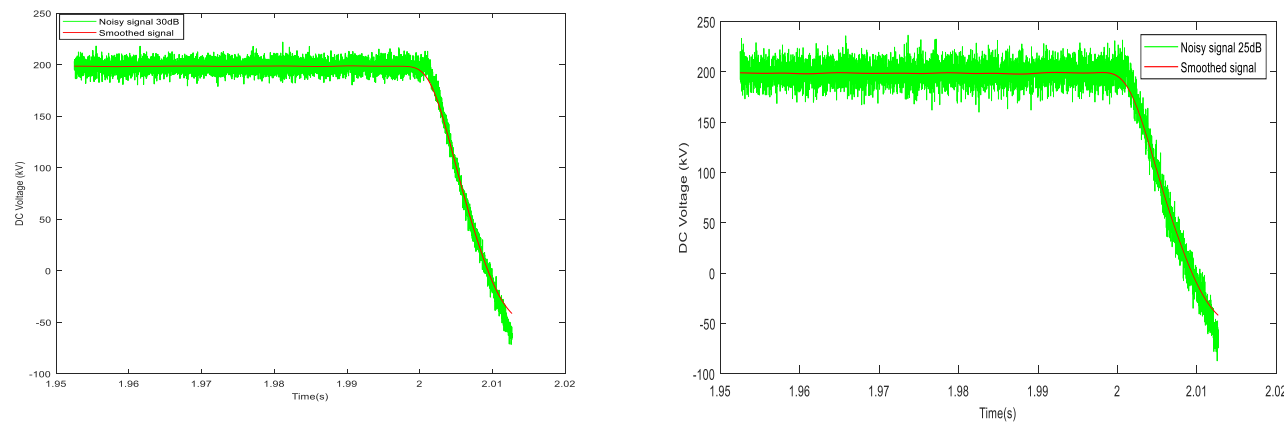

Fig. 4.9 Noisy and Smoothed Current Waveform measured at the relay R12, with signal to noise ratios for external fault: (a)50dB; (b) $40 \mathrm{~dB}$ (c)30dB (d)25dB The calculated travelling wave power considering a SNR of $40 \mathrm{~dB}$ for internal and
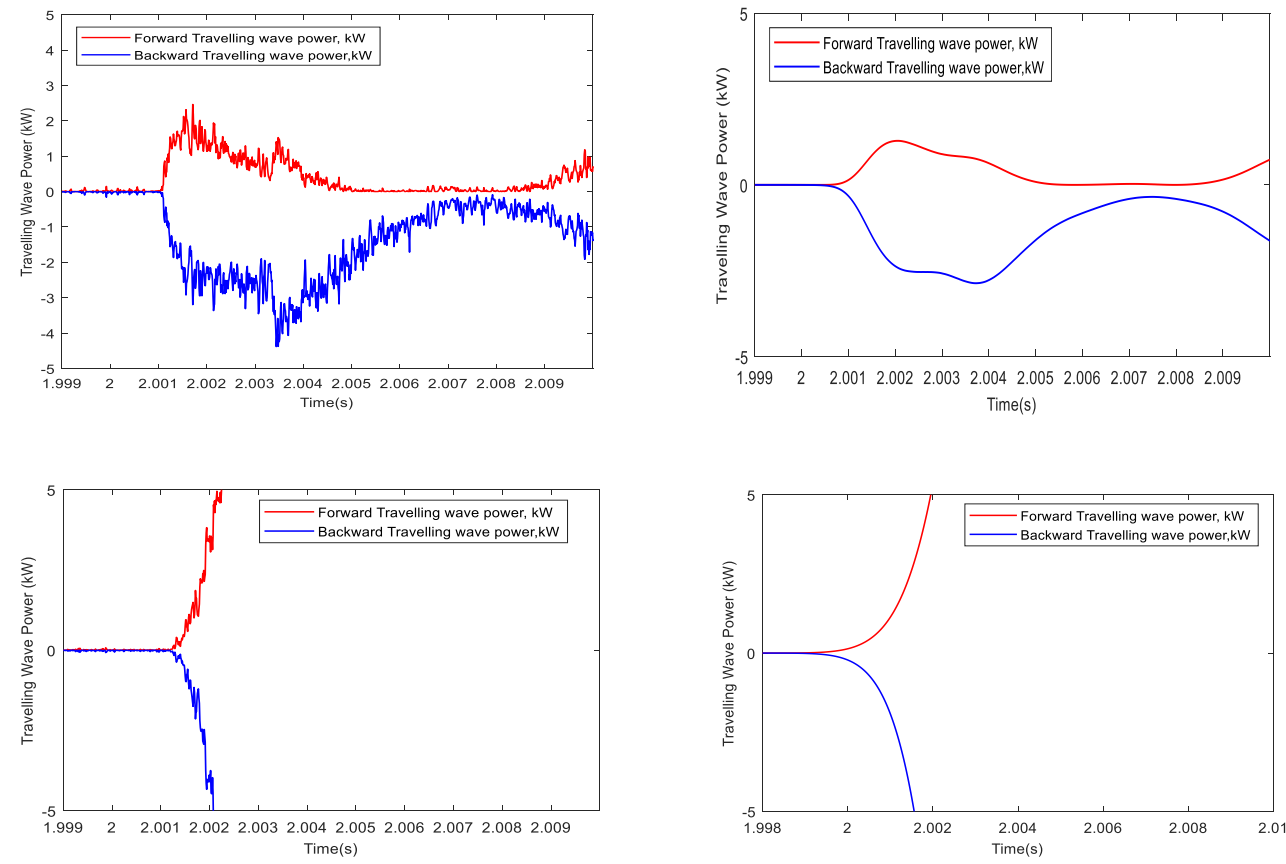

Fig. 4.10 Calculated PFW and PBW for Noisy and Smoothed travelling wave components measured at the relay $R 12$, with signal to noise ratio of $40 \mathrm{~dB}$ (a)Noisy internal fault; (b) Smoothed internal fault (c)Noisy external fault (d)smoothed external fault.

whilst external fault are shown in Figure 4.10. As, shown, there is a significant reduction in the peaks as well as a shift in the travelling wave components waveform. However, this does not matter, because as far the relay is concerned, the arrival time of the first incident wave at the relay terminal is regarded at $t_{0}$. In this scenario, the calculated $E_{F W}$ and $E_{B W}$ were $9.4455 \mathrm{e}-06$ and $1.3962 \mathrm{e}-05$ and $3.7469 \mathrm{e}-05$ and 9.6604e-05 for external fault respectively. Clearly, from the plots, the application of the filter has impacted on the shape of the wave shape which ultimately results in 
significant differences in the calculated EFW and $E_{B W}$ compared to those give in table 2. Generally, the assumption of a 500 internal and 0.01 external fault gives a worstcase scenario for the relay, hence taken as the most critical condition for the relay in this study.

In this study, the decision to declare internal or external fault on a section on the DC link was made at $0.5 \mathrm{~ms}$ following the application of fault. The results presented shows that this was achieved during this time frame. Noting that prototype HVDC breakers available in literature operates at 2 - 5ms [34,35], a total fault clearance time of $2.5-$ $5.5 \mathrm{~ms}$ can be achieved; assuming the time delay in the hardware is negligible. The total fault clearance time is also largely dependent on the operating speed of the HVDC breaker. The computational requirements for the protection scheme includes voltage and current transduces which can capture the high frequency transient signal such as optical voltage and current transducers installed on the DC line; digital filters to filter the high frequency noise as well modern digital relay having the capability of sampling at $96 \mathrm{kHz}$ or more.

\section{Conclusions}

This paper presents a novel DC line protection technique utilising travelling wave energy for application to DC grids. Firstly, the ratio between the forward travelling wave energy and the backward travelling wave energy was used to provide directional discrimination. Secondly, the magnitudes of the travelling wave energy for a pre-set time duration following the occurrence of a fault provided discrimination between internal and external fault. For an internal fault, both the ratio criteria (less than unity) and magnitude criteria (exceeding a predetermined setting) must be satisfied. To 
increase the security and stability of the proposed protection algorithm, a negative fault discriminative element was incorporated into the protection scheme. All simulations were carried out in PSCAD and the resulting data exported to MATLAB workspace for post processing. A key feature of the proposed directional comparison protection technique is that the cable distance does not have any appreciable effect on the protection scheme; and hence would not have any effect on the reliability and the integrity of the protection scheme. This implies that the ratio, $E_{F W} / E_{B W}$ will always be less than unity for all forward directional faults.

This study focuses on fault detection on the DC link, hence the effect of the converter operation on the proposed protection principle was not considered in this paper, but shall form a basis for future work. The reliability of the protection scheme is largely dependent on the accuracy in determining the protection threshold. In this study, the protection threshold was arrived at by considering the worst case fault scenario for the local relay. However, for practical applications, this will be compromise considering the grid configuration and the time required for total fault clearance. Once the cable parameters are known, the protection threshold can be determined off site. The short data window chosen in this paper was found to provide sufficient samples $(N=48)$ needed for fault discrimination. Generally, as the relay signal uses the magnitude of the travelling wave energy, which is representative of the area under the travelling wave power curve, an oscillation in the travelling wave power curve during the measurement period will not have any appreciable effect on the accuracy of the measured relay signal. Although attempt have been made in this study to investigate the effect of noise on the proposed protection method by simulating a signal corrupted by a guasian (white noise) and thereafter using a filter to extract the noise; however as travelling wave are accopnaing by non-uniform noise of varying degrees of frequencies, consideration shall be give to this in future work. However, as this study is based on results from PSCAD simulations, the obtained signal was assumed to be 
the trend in the actual signal, and hence was used to prove the protection principle as per proof-of-concept. The proposed algorithm has been investigated against two main types of faults in DC grids, namely pole-pole $(P-P)$ and pole -pole $(P-P)$ faults. Although majority of faults in DC cables would be P-G fault, however since a P-P fault would results in larger magnitude of fault current which can damage the converter, they were also investigated in this paper. In case of failure of the primary protection scheme, a back-up protection strategy utilising the travelling wave energy ratios at both local and remote end relay terminals is a possible solution. For an internal fault, the travelling wave energy ratio at both relay terminals are less than unity, whereas for an external fault the ratio is less unity at one terminal and greater than unity at the other relay terminal. Studies shall also continue in this regard and the findings shall be reported in a separate document.

\section{Acknowledgements}

Special thanks are due to the management and staff of GE Grid Solutions, Stafford. Thanks also goes to Staffordshire University for providing the enabling environment to undertake this research project.

\section{Funding Source}

The work was supported by General Electric Grid Solutions, Stafford - UK , 2015.

\section{Reference}

[1]D. Jovcic, D.V. Hertem, K. Linden, J. Taisen, W. Grieshaber, Feasibility of DC transmission networks, $2^{\text {nd }}$ IEEE PES Int. Conf. Exhib. Innov. Smart Grid Technology, Manchester, UK, December 2011, pp. 1-8.

[2]C.D. Barker, R. S. Whitehouse, An Alternative Approach to HVDC Grid Protection, $10^{\text {th }}$ IET Int. Conf. (ACDC2012), Birmingham, May 2012, pp. 1-6

[3]J. Sneath, A.D. Rajapakse, Fault Detection and Interruption in an Earthed HVDC Grid using ROCOV and Hybrid DC Breakers, IEEE Trans. Power Deliv. 31 (2016) pp. 973-981. 
[4]A. Adamczyk, C.D. Barker, H. Ha, Fault Detection and Branch Identification for HVDC Grids, $12^{\text {th }}$ IET Int. Conf., (DPSP2014), Copenhagan, Denmark, 2014, pp. 1-6.

[5]J. Descloux, B. Raison, J. Curis, Protection strategy for undersea MTDC grids, IEEE conf., (POWERTECH), 2013, Grenoble, pp 1-6.

[6]D. K. Kerf, K. Srivastava, M. Reza, D. Bekaert, S. Cole, D. V, Hertem, R. Belmans, 'Wavelet-based protection strategy for DC faults in multi-terminal VSC HVDC systems, IET Gener. Transm. Distrib., 5 (2011) ,pp 496-503.

[7]W. Leterme, J. Beerten, D.V. Hertem, Non-unit protection of HVDC grids with inductive DC cable termination," IEEE Trans. Power Deliv., 31(2015), pp. 820-828.

[8]J. Liu, N. Tai, C. Fan, Transient-Voltage Based Protection Scheme for DC line faults in multi-terminal VSC - HVDC system', IEEE Trans., 32 (2017), pp 1483-1494.

[9]I. Dallas, C. Booth, Teleprotection in multi-terminal HVDC supergrids, $12^{\text {th }}$ IET Int. Conf., (DPSP2014), Copenhagan, Denmark, 2014, pp. 1-6.

[10]J. Wang, B. Berggren B, K. Linden, J. Pan, R. Nuqui, Multi-Terminal DC System line Protection Requirement and High Speed Protection Solutions, CIGRE, Lund, Sweden, 2015,pp 1-9

[11]M. Ikhide, S. Tennakoon, A Griffiths, S. Subramanian, H. Ha, Fault detection in Multi-Terminal Modular Multilevel Converter (MMC) based High Voltage DC (HVDC) transmission system', IEEE conf. (UPEC), Stoke-on-Trent, UK, 2015 pp1-6

[12]C. Troitzsch, A. K. Marten, D. Westermann, Non-telecommunication based DC line fault detection methodology for meshed HVDC grids'IET Gener. Transm. Distrib., 10 (2016) pp. 4231-423

[13]A.E.B , Abu-Elaniena, A. S. Abdel-Khalik, A. M. Massoud, S. Ahmed, A noncommunication based protection algorithm for multi-terminal HVDC grids; Electric Power Systems Research 144 (2017) 41-51.

[14]G. Zoua, Q. Fengb, Q. Huanga, Q. Sunc, H. Gaoa, A fast protection scheme for VSC based multi-terminal DC grid, Electrical Power and Energy Systems, 98 (2018), pp 307-314

[15]A.E.B, Abu-Elaniena, A. S. Abdel-Khalik, A. M. Massoud, S. Ahmed, A differential protection technique for multi-terminal HVDC, Electric Power Systems Research, 130 (2016), pp 78-88.

[16]Li Yan, Yanfeng Gong, and Bin Jiang. "A novel traveling-wave-based directional protection scheme for MTDC grid with inductive DC terminal", Electric Power Systems Research 157 (2018): 83-92

[17]HVDC benefits, https://www.energy.siemens.com/hq/en/power-transmission/hvdc/applicationsbenefits/hvdc-benefits.htm\#content=Economic\%20Aspects (Accessed 2 July, 2018)

[18]Liu Zhenya Liu," Ulta high voltage AC/DC grids, Elsevier , UK, 2015 
[19]Y. Kato, A. Watanabe, H. Konishi, T. Kawai, Y. Inoeu, M. Sanpei, Cable Section Fault Detection for HVDC Line Protection, IEEE Transactions on Power Delivery, 1(1986), pp. $332-336$.

[20]M.X. Li, J.H. He, Z.Q. Bo, H.T. Yip, L. Yu, A. Klimek, Simulation and algorithm development of protection scheme in DC traction systems", IEEE POWERTECH Conference, Romania, 2009, pp 1-6.

[21]P. A. Crossley, P.G. McLaren, Travelling Wave based Distance Protection, IEEE Trans. Power App \& Sys., PAS(1983), pp $2971-2983$.

[22]A. T. Johns, New ultra-high-speed directional comparison technique for the protection of EHV . transmission lines', IEE proc., 127,(1980), pp 228-239.

[23]M. Chamia, S. Liberman, Ultra High Speed Relay for EHV/UHV Transmission Lines-Development, Design and Applications, IEEE Trans., PAS97(1978), pp. 2104 2116.

[24]C. Christopoulos, D.W.P. Thomas, Scheme based on travelling wave for the protection of major transmission lines, IEE proceedings, 135 (1988),pp 63 - 73

[25]D. Naidoo, M.N. Ijumba, A Protection System for Long HVDC Transmission Lines", Power Engineering Society Inaugural Conference and Exposition, Durban South Africa, July, 2005, pp. $150-155$

[26]H. Ha, Y. Yang, Y. RuiPeng, Z. Bo, C. Bo, Novel Scheme of Travelling wave based differential protection for bipolar HVDC Transmission Lines, IEEE Conference (POWERCON2010), China, 2010.

[27]B. Zhang, H. Ha, J. Duan, Z. Bo, Boundary Protection, A New Concept for Extra High Voltage Transmission Lines --- Part I: IEEE/PES Transmission and Distribution Conference \& Exhibition: Asia and Pacific Dalian, China

[28]Z. Ying Z, T. Nengling, X. Bin, Fault Analysis and Traveling-Wave Protection Scheme for Bipolar HVDC Lines, IEEE Transactions on Power Delivery, 27(2002), pp 1-6

[29]L. Xiaolei, A.H. Osman, O. P. Malik, Hybrid Traveling Wave/Boundary Protection for Monopolar HVDC Line', IEEE Transactions on Power Delivery, Vol. 24, No. 2, April 2009

[30]Implementing the protection and control of future HVDC grids, Think Grid', http://www.think-grid.org/implementing-protection-and-control-future-hvdc-grids, (accessed 2 May, 2018)

[31] Manitoba HVDC Research', Four Terminal DC test Grid, 2014, https://hvdc.ca/

[32] G. Jakob, H. Jesper, H. K. Lukasz, L.B. Claus, Review on multi-level voltage source converter based HVDC technologies for grid connection of large offshore wind farms", IEEE Int. Conference (POWERCON), New Zealand, 2012; pp 1-6.

[33]A. P. Grain, W.W. Barry, Half- and Full-Bridge Modular Multilevel Converter Models for Simulations of Full-Scale HVDC Links and Multiterminal DC Grids, IEEE Journal of Emerging and Selected Topics in Power Electronics, 2(2), pp 1089 - 1108 
[34]C. C. Davidson; R. S. Whitehouse; C. D. Barker; J. P. Dupraz; W. Grieshaber, A new ultra-fast HVDC Circuit breaker for meshed DC networks, $11^{\text {th }}$ IET Int. Conference (ACDC),pp 1-7, 2015.

[35]M. Callavik and A. Blomberg, "The Hybrid HVDC Breaker An innovation breakthrough enabling reliable HVDC grids," 2012.

[36]Xinzhou Dong, Yaozhong Ge, Jiali He, Surge Impedance Relay, IEEE trans., 20(2), pp 1247 - 12562005

[37]Xiaolei Liu, A.H. Osman, O.P. Malik, Hardware Implementation of a Hybrid Protection Scheme for Bipolar HVDC Line, International Conference on Electric Power and Energy Conversion Systems, (EPECS), UAE, 2009.

[38]P Li, Y. Zheng, C. Han, L. Song, B. Co, Wavelet threshold methods Used in lightning transient electrical signals de-noising, 9th International Conference on Fuzzy Systems and Knowledge Discovery (FSKD 2012), pp 1-6, 2012

[39]Z. Ji, D. Shi, Q. LI, Q.H. Wu, Noise Reduction and Confidence Level Analysis in MMG-based Transient Fault Location, IEEE/PES Transmission \& Distribution Conference \& Exposition: Asia and Pacific, China, pp1-6,2005.

[40]Y. Xi, Z. Li, X. Zeng, X. Tang, X. Zhang, H. Xiao, Fault location based on travelling wave identification using an adaptive extended Kalman filter", IET Gener. Transm. Distrib., 2018, 12(6), pp. 1314-1322 


\section{Appendix 1}

Table 6 Converter and AC side Parameters [29]

\begin{tabular}{ll}
\hline Item & Ratings \\
\hline Rated Power of Converter & $800 \mathrm{MVA}$ \\
Rated DC Voltage of Converter $(P-P)$ & $400 \mathrm{kV}$ \\
Converter arm inductance & $29 \mathrm{mH}$ \\
Cell DC Capacitor & $10000 \mu \mathrm{F}$ \\
Nominal Frequency & $50 \mathrm{~Hz}$ \\
Transformer nominal voltage $(L-L) R M S$ & $380 \mathrm{kV}$ \\
Nominal voltage at VSC side $(L-L) R M S$ & $220 \mathrm{kV}$ \\
Leakage reactance of transformer & $0.18 \mathrm{pu}$ \\
Rated real power per phase of Load $_{\text {Rated reactive power per phase of Load }}$ & $33 \mathrm{MW}$ \\
Rated load voltage $(L-G)$ RMS & $0.0 \mathrm{MW}$ \\
& $83.72 \mathrm{kV}$ \\
\hline
\end{tabular}

\section{Appendix 2}

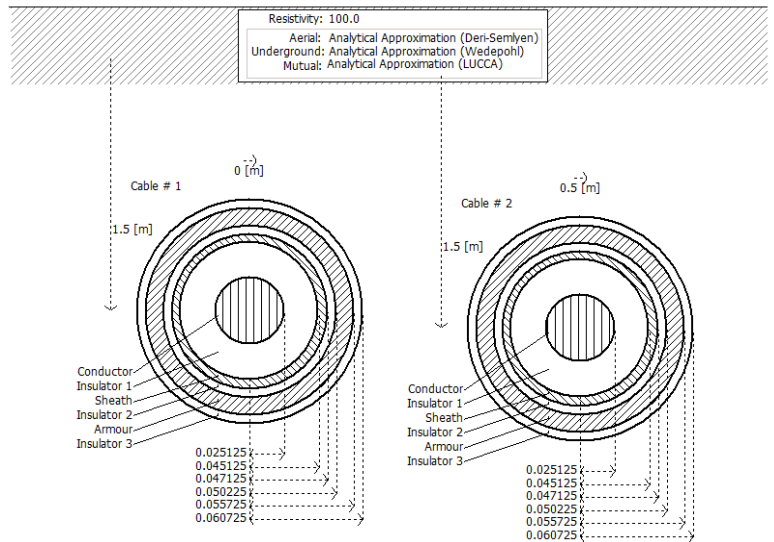

Fig. 7 Cable configuration [29]

Table 7 Conductor and Insulation Parameters [29]

\begin{tabular}{ll}
\hline Item & Ratings \\
\hline Resistivity of core conductor & $2.2 \times 10^{-8} \Omega \mathrm{m}$ \\
Resistivity of $1^{\text {st }}$ conducting layer (sheath) & $27.4 \times 10^{-8} \Omega \mathrm{m}$ \\
Resistivity of $2^{\text {nd }}$ conducting layer & $18.15 \times 10^{-8} \Omega \mathrm{m}$ \\
Outer radius of core conductor & $2.51 \times 10^{-2} \mathrm{~m}$ \\
Thickness of $1^{\text {st }}$ conducting layer & $2 \times 10^{-3} \mathrm{~m}$ \\
Thickness of $2^{\text {nd }}$ conducting layer & $5.5 \times 10^{-3} \mathrm{~m}$ \\
Thickness of $1^{\text {st }}$ insulation layer & $2 \times 10^{-2} \mathrm{~m}$ \\
Thickness of $2^{\text {nd } \quad \text { insulation layer }}$ & $3.1 \times 10^{-3} \mathrm{~m}$ \\
Thickness of $3^{\text {rd } \quad \text { insulation layer }}$ & $5 \times 10^{-3} \mathrm{~m}$ \\
Relative permittivity of all insulation layer & 2.3 \\
All relative permeability & 1 \\
Ground resistivity & $100 \Omega \mathrm{m}$ \\
Length of Cable & $200 \mathrm{~km}$ \\
\hline
\end{tabular}


